\title{
A Fast Simulation Method for Wave Transformation Processes In Coastal Zones
}

\author{
I.E Herrera-Díaz ${ }^{* 1}$, C. Couder-Castañeda ${ }^{2}$, H. Ramírez León ${ }^{2}$ \\ ${ }^{1}$ Centro de Investigación en Matemáticas, AC. \\ Jalisco S/N, Col. Valenciana, CP 36240 \\ Guanajuato, Gto, Mexico. \\ *enriquehd@cimat.mx \\ ${ }^{2}$ Mexican Petroleum Institute, \\ Eje Central Lázaro Cárdenas 152, CP 07730 \\ Mexico City, Mexico.
}

\begin{abstract}
We develop a numerical model based on the mild-slope equation of water wave propagation over complex bathymetrys, taking into account the combined effects of refraction, diffraction and reflection due to protection structures. The numerical method was developed using a split proposed version of the mild-slope equation in elliptical form and solved by an implicit method in a finite volume mesh, this technique easily allows the modeling of the wave transformations caused by the protection structures in coastal waters, where industrial and other economic activities take place. Study cases controlled have been made and the results match very well with the reference solution. The capability and utility of the model for coastal areas are illustrated by its application to the breakwater of the Laguna Verde Nuclear Power Plant (LVNPP) and the protection structure of the Nautical Marine named "Los Ayala".
\end{abstract}

Keywords: near-shore, wave transformation, protection structures, implicit method.

\section{RESUMEN}

Se desarrolla un método numérico para resolver la ecuación de la pendiente suave, para el estudio de la propagación del oleaje en batimetrías complejas, tomando en cuenta los efectos combinados de la refracción, difracción y reflexión causados por estructuras de protección. El método numérico se basa en la descomposición de la ecuación de la pendiente suave en su forma elíptica para resolverla por un método implícito en volúmenes finitos. Esta técnica permite la modelación de las transformaciones del oleaje causadas por las estructuras de protección en aguas costeras, donde actividades industriales y recreativas tienen lugar. Casos de estudio controlados fueron hechos y los resultados coinciden con la solución de referencia. La capacidad y utilidad del modelo para aguas costeras es ilustrado con la aplicación al rompeolas de la Planta Nuclear de Laguna Verde y la estructura de protección en la Marina Náutica "Los Ayala".

\section{Introduction}

Recently, great deals of public concern and interest have been directed towards the coastal waters, where industrial activities take place. As a result, engineers are facing an increasing demand for solutions to coastal problems among which are the understanding of the water wave transformation over the complex bathymetry, from deep water to shallow sloping beaches, which dominates various aspects of coastal hydrodynamics processes, especially the generation of alongshore currents as well as sediment transport.
The mild-slope equation (MSE) based on wave models emerged in the late 1960s and reached full maturity by the early 1990s. A number of free and commercially MSE models are available today such as CGWAVE and CREDIZ models, but it is not possible to use them in the field because engineers do not have enough time to create the meshes and wait for the results in field. The key to the model presented is the previous calculus of some important near-shore wave processes such as wave current and wave-wave interactions made with a research hydrodynamic model early developed [19]. 
The MSE which describes the propagation of periodic, small amplitude surface gravity waves over a seabed of mild slope was first established by Berkhoff [1]. This original equation takes into account the combined effects of refraction, diffraction and reflection, while the influence of wave breaking, bottom friction, currents and wind are neglected; for this reason, we utilize a hydrodynamic model [19] to calculate these effects.

The solution of the MSE was obtained by using the finite-element method [8, 23], and finite-differences schemes [5, 12]; however, this mild-slope equation is essentially of an elliptic type and, therefore, its solution is very difficult due to the necessity of giving boundary conditions along the closed curve and the requirement of solving a large number of simultaneous linear systems of equations. Some efforts to develop an efficient method for wave propagation could be seen in [17] where is used two iterative solvers based on the Bi-Conjugate Gradient Method. Some current finite difference methods on the hyperbolic form of the mild-slope equation used to accelerate the computation was presented by $[22,26]$ where is used predictorcorrector scheme and the three-point finite difference method. A compact explicit finite difference method was presented by [14], and a explicit scheme by $[13,10]$.

Some recent approaches based on finite volume was developed by [9], the domain transformation of the MSE in curvilinear coordinates using a ADI as solution method could be seen in [24] and a spectral approach can be found at [27]. A similar work related to this research is the numerical simulation of engineering wave for zhongzui bay [21].

The numerical restriction of the elliptical form of the MSE makes it computationally costly to find the solution for short waves over a larger area. To overcome this problem, in this research the MSE is split in tree equations to perform the calculations of the phase velocity and wave height.

The proposed numerical scheme requires the solution of a tri-diagonal and pent-diagonal systems to solve the phases and the wave height respectively. The type of grid used is the staggered cell with the possibility of a grid refinement in zones of interest. The numerical code developed was coupled with a hydrodynamic code [20, 2, 7, 3, 4] which provides the hydrodynamic field in the study area. The numerical code was proved with examples where the analytical solution exists and have constant conditions obtaining acceptable values with a numerical error less than $1 \%$ compared with the exact solution.

The study cases are the protection structure of the Laguna Verde Nuclear Power Station located on the coast of the Gulf of Mexico and the Nautical Marine Los Ayala located on the coast of the Pacific Ocean. The real meteorological parameters and the data of the waves direction of the areas were acquired in order to obtain more accurate results.

\section{Mathematical model}

The propagation of periodic, small amplitude, linear surface waves over a seabed of mild slope can be described by the equation below [18]:

$$
\nabla\left(C c_{g} \nabla \eta\right)-\frac{c_{g}}{C} \frac{\partial^{2} \eta}{\partial t^{2}}=0
$$

where $\eta$ is the wave height, $C$ is the phase velocity and $C_{g}$ is the group velocity.

The Eq. (1) accounts for the combined effects of refraction, diffraction and reflection and can be used for the computation of wave propagation in coastal regions and for the computation of wave transformation with a reflecting boundary such as harbor or breakwater [6]. However, it is essentially of elliptic form, and its solution needs a boundary condition along the closed curve and a great amount of computing time and storage. Therefore for short waves over an open coast area, it is infeasible.

The aim of the numerical solution proposed for the Eq. (1) is to split the equation, in its phase velocities components $x$ and $y$ and the wave height $\eta$. The equations for the phase velocities $Q x$ and $Q y$ in the direction $x$ and $y$ respectively are expressed as:

$$
c^{2} \frac{\partial \eta}{\partial x}=-\frac{\partial Q_{x}}{\partial t}
$$




$$
c^{2} \frac{\partial \eta}{\partial y}=-\frac{\partial Q_{y}}{\partial t} .
$$

The wave height is determined by:

$$
\frac{\partial \eta}{\partial t}=-\frac{1}{n}\left[\frac{\partial}{\partial x}\left(n Q_{x}\right)+\frac{\partial}{\partial y}\left(n Q_{y}\right)\right],
$$

where $n$ (group factor) is defined as follows:

$$
n=\frac{1}{2}\left(1+\frac{2 k h}{\sinh (2 k h)}\right)
$$

$k$ denotes the wave number and $h$ the depth.
The advantage of splitting the general Eq.(1) in the Eqs. (2), (3) and (4) is the modeling of breakwaters in a simple manner.

\section{Numerical scheme}

The numerical solution of the Eqs.(2), (3) and (4) is performed using a staggered grid illustrated in Figure1, in the grid wave height is calculated at the solid grid points, labeled $(i-1, j),(i, j),(i+1, j),(i, j-1),(i$, $j+1)$, etc., and the velocities are calculated at the open grid points, labeled $(i-1 / 2, j),(i+1 / 2, j),(j+1 / 2, i),(j-1 / 2$, $i)$. Specifically, $x$ is calculated at points $(i-1 / 2, j),(i+1 / 2, j)$ and $y$ is calculated at different points $(j+1 / 2, i),(j-1 / 2, i)$. The key feature here is that wave height is calculated at different grid points. In the Figure 1, the open grid points are shown equidistant between the solid grid points, but this is not a necessity.

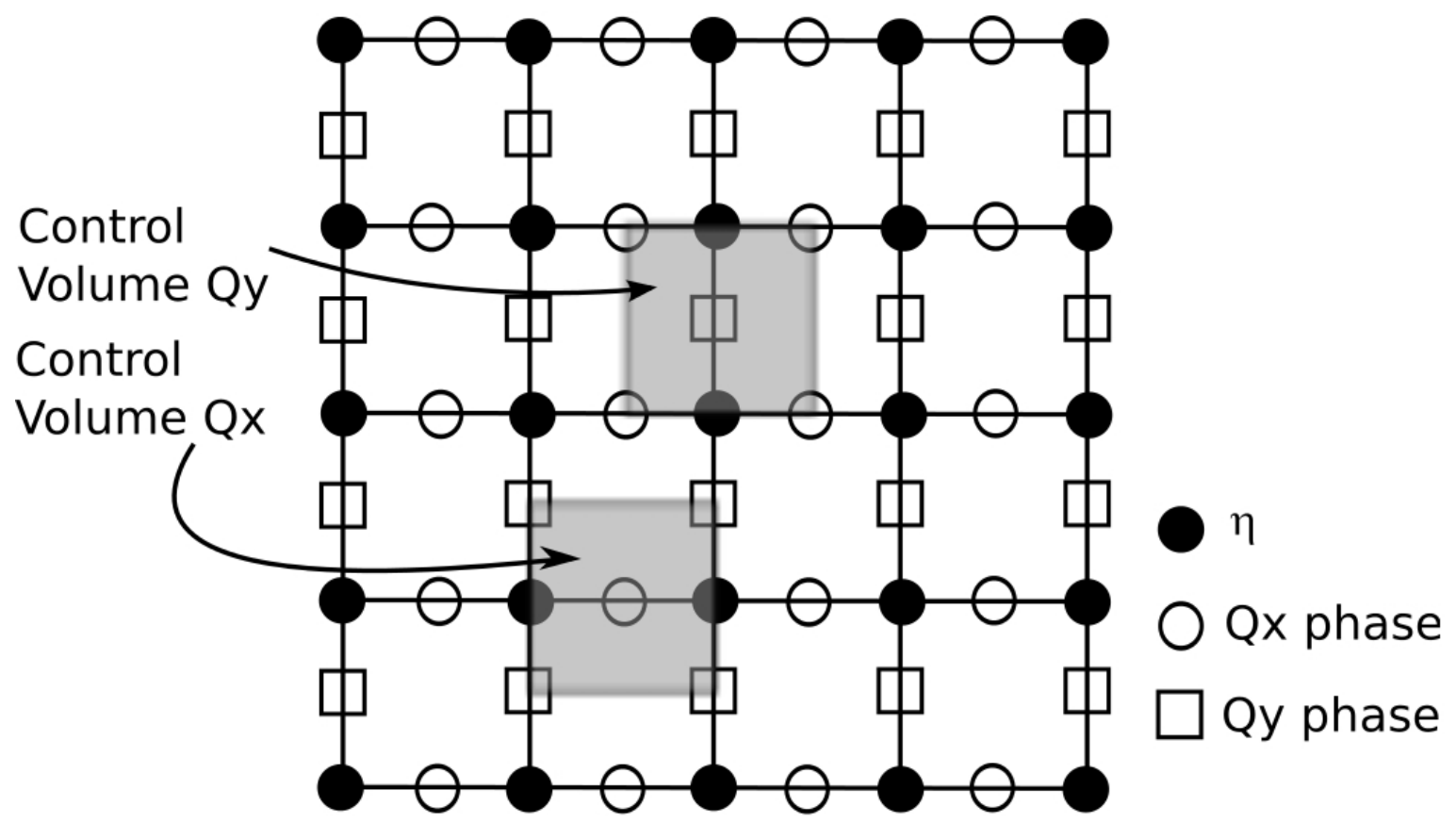

Figure1. Computational domain for staggered grid. 


\section{A Fast Simulation Method for Wave Transformation Processes In Coastal Zones, I.E Herrera-Díaz et al., 243-266}

The discretization of the Eq. (2) proceeds as follows:

Analogous for the Eq. (3) the discretization is expressed as:

$$
\begin{array}{ll}
\frac{1}{C_{i-1, j+\frac{1}{2}}^{2}} Q x_{i-1, j+\frac{1}{2}}^{t+1}+\frac{22}{C_{i, j+\frac{1}{2}}^{2}} Q x_{i, j+\frac{1}{2}}^{t+1}+\frac{1}{C_{i+1, j+\frac{1}{2}}^{2}} Q x_{i+1, j+\frac{1}{2}}^{t+1}= & \frac{1}{C_{i+\frac{1}{2}, j-1}^{2}} Q y_{i+\frac{1}{2}, j-1}^{t+1}+\frac{22}{C_{i+\frac{1}{2}, j}^{2}} Q y_{i+\frac{1}{2}, j}^{t+1}+\frac{1}{C_{i+1, j+\frac{1}{2}}^{2}} Q y_{i+\frac{1}{2}, j+1}^{t+1}= \\
\frac{1}{C_{i-1, j+\frac{1}{2}}^{2}} Q x_{i-1, j+\frac{1}{2}}^{t}+\frac{22}{C_{i-1, j+\frac{1}{2}}^{2}} Q x_{i-1, j+\frac{1}{2}}^{t}+ & \frac{1}{C_{i+\frac{1}{2}, j-1}^{2}} Q y_{i+\frac{1}{2}, j-1}^{t}+\frac{22}{C_{i+\frac{1}{2}, j}^{2}} Q y_{i+\frac{1}{2}, j}^{t}+ \\
\frac{1}{C_{i-1, j+\frac{1}{2}}^{2}} Q x_{i-1, j+\frac{1}{2}}^{t}-\frac{24}{\Delta x}\left(\eta_{i+\frac{1}{2}, j+\frac{1}{2}}^{t}-\eta_{i-\frac{1}{2}, j+\frac{1}{2}}^{t}\right) & \frac{1}{C_{i+\frac{1}{2}, j+1}^{2}} Q x_{i+\frac{1}{2}, j+1}^{t}-\frac{24}{\Delta y}\left(\eta_{i+\frac{1}{2}, j+\frac{1}{2}}^{t}-\eta_{i+\frac{1}{2}, j-\frac{1}{2}}^{t}\right)
\end{array}
$$

The Figure 2 shows the computational molecule for the calculation of $Q x$.

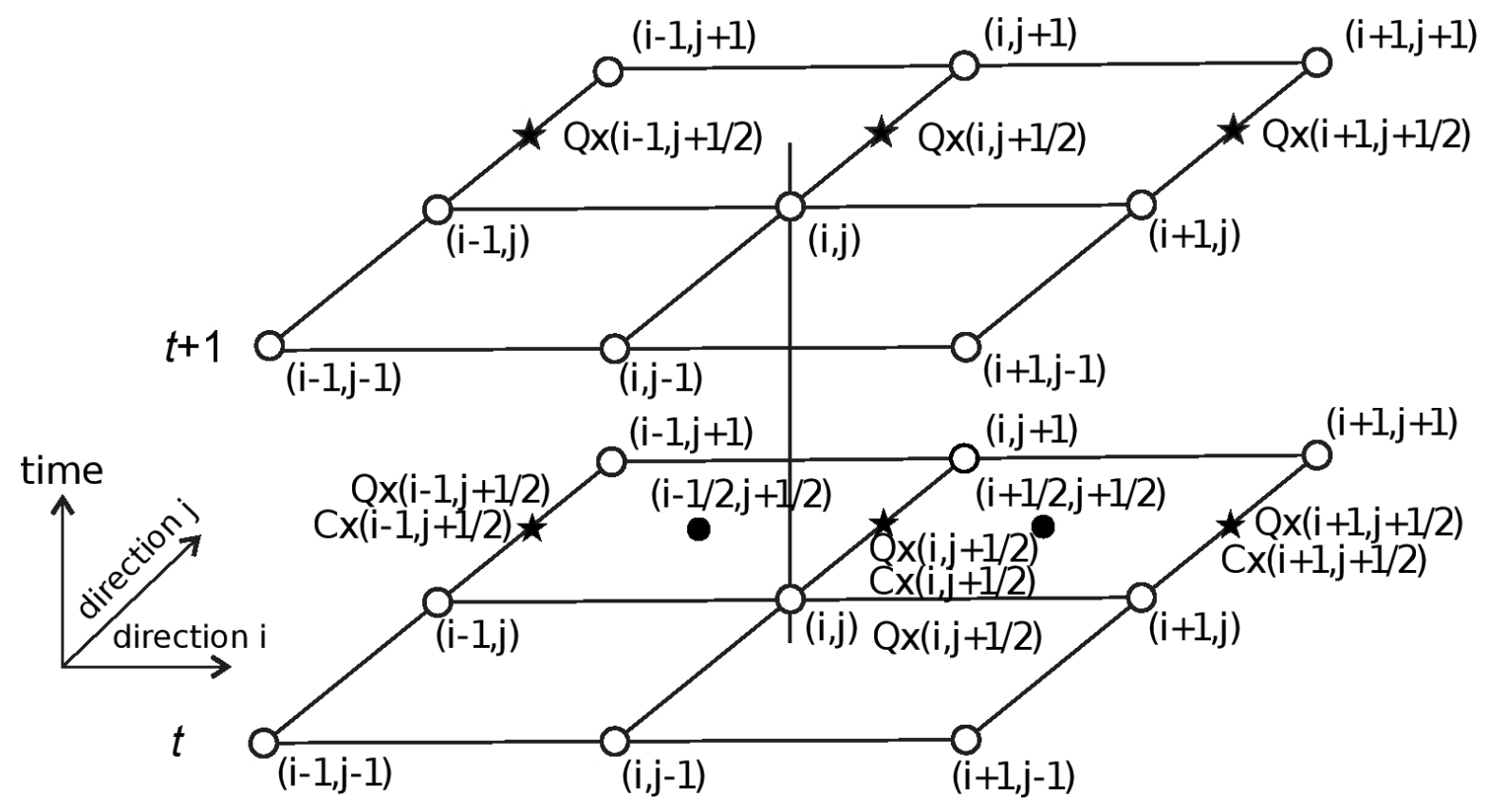

Figure2. Computational domain for the calculation of $Q x$ 
The solution of the Eqs. (6) and (7) produces a tridiagonal system for every row $i$ and $j$ column, this implies that we have to solve $n i \times n j$ lineal systems, for this reason is important to have an efficient method, in this research we use the Thomas algorithm. The Figure 3 shows the computational molecule for the calculation of $Q y$.

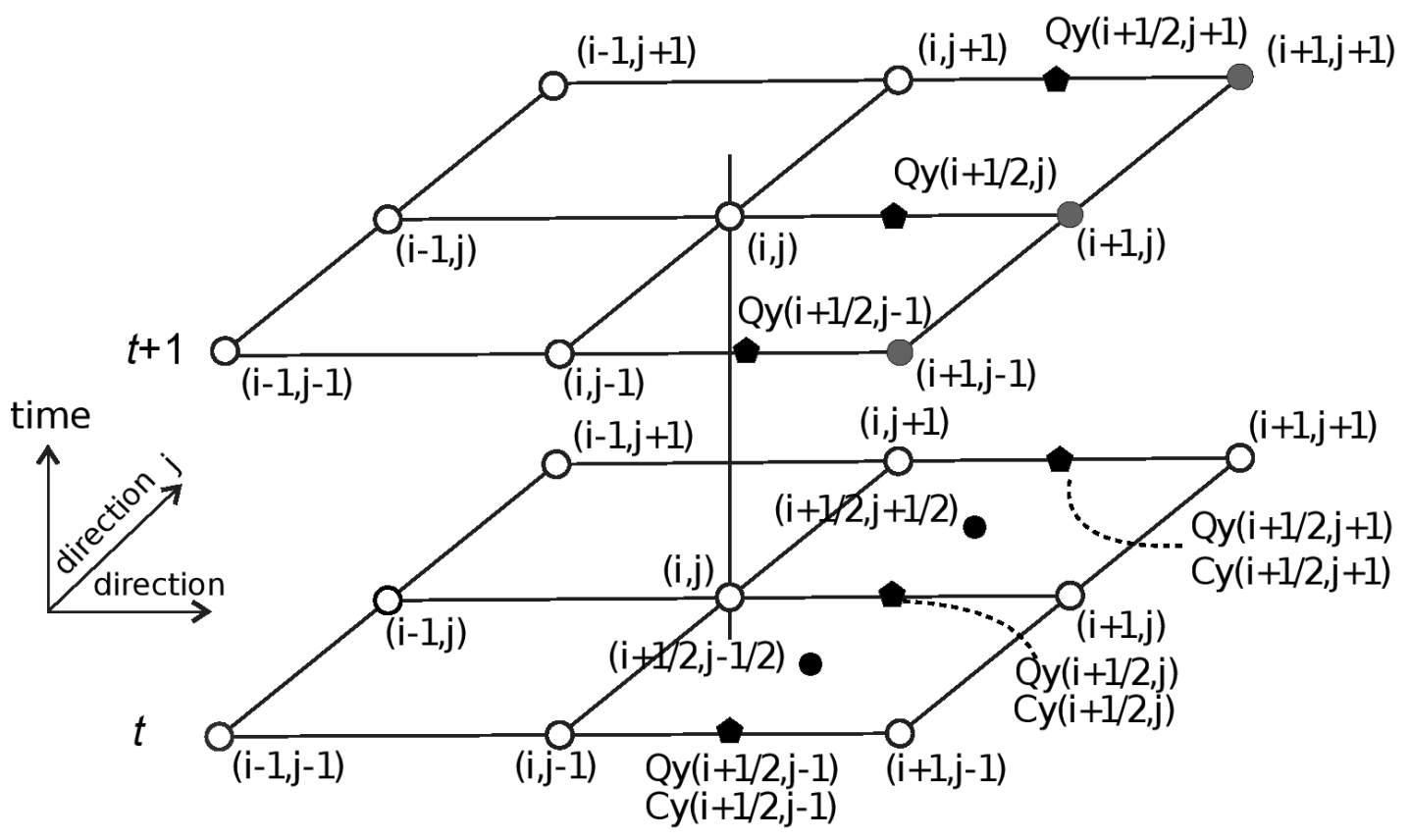

Figure3. Computational domain for the calculation of $Q y$.

$$
\begin{aligned}
& \left(n_{i-1 / 2, j+1 / 2} \eta_{i-1 / 2, j+1 / 2}^{t+1}\right)+\left(n_{i+3 / 2, j+1 / 2} \eta_{i+3 / 2, j+1 / 2}^{t+1}\right)+\left(n_{i+1 / 2, j-1 / 2} \eta_{i+1 / 2, j-1 / 2}^{t+1}\right)+ \\
& \left(n_{i+1 / 2, j+3 / 2} \eta_{i+1 / 2, j+3 / 2}^{t+1}\right)+\left(20 n_{i+1 / 2, j+1 / 2} \eta_{i+1 / 2, j+1 / 2}^{t+1}\right)= \\
& \left(n_{i-1 / 2, j+1 / 2} \eta_{i-1 / 2, j+1 / 2}^{t}\right)+\left(n_{i+3 / 2, j+1 / 2} \eta_{i+3 / 2, j+1 / 2}^{t}\right)+\left(n_{i+1 / 2, j-1 / 2} \eta_{i+1 / 2, j-1 / 2}^{t}\right)+ \\
& \left(n_{i+1 / 2, j+3 / 2} \eta_{i+1 / 2, j+3 / 2}^{t}\right)+\left(20 n_{i+1 / 2, j+1 / 2} \eta_{i+1 / 2, j+1 / 2}^{t}\right)- \\
& \left(\frac{\Delta t}{\Delta x}\right)\left(n_{i+1, j-1 / 2} Q_{x_{i+1, j-1 / 2}^{t+1}}^{t}-n_{i, j-1 / 2} Q_{x i, j-1 / 2}^{t+1}+n_{i+1, j+3 / 2} Q_{x_{i+1, j+3} / 2}^{t+1}-n_{i, j+3 / 2} Q_{x_{i, j+3} / 2}^{t+1}\right)- \\
& \left(\frac{\Delta t}{\Delta y}\right)\left(n_{i-1 / 2, j+1} Q_{y_{i-1 / 2, j+1}}^{t+1}-n_{i-1 / 2, j} Q_{y_{i-1 / 2, j}}^{t+1}+n_{i+3 / 2, j+1} Q_{y_{i+3} / 2, j+1}^{t+1}-n_{i+3 / 2, j} Q_{y_{i+3} / 2, j}^{t+1}\right)- \\
& 22\left(n_{i+1, j+1 / 2} Q_{x i+1, j+1 / 2}^{t+1}-n_{i, j+1 / 2} Q_{x i, j+1 / 2}^{t+1} n_{i+1 / 2, j+1} Q_{y_{i+1} / 1, j+1}^{t+1}-n_{i+1 / 2, j} Q_{y_{i+1} / 2, j}^{t+1}\right)
\end{aligned}
$$




\section{A Fast Simulation Method for Wave Transformation Processes In Coastal Zones, I.E Herrera-Díaz et al., 243-266}

The last Eq. (8) is a fourth-order-accurate and produces a pent-diagonal banded lineal system. Such system requires the previous calculated phases $(Q x, Q y)$, and the wave height in the previous time. We utilize a sparse matrix iterative method to solve the system.

The values of $\eta, Q x, Q y$, could be zero at time $t=0$ except at the boundaries where the waves are incidents, this condition is necessary to determine the new values at time $(t+\Delta t)$. The Figure 4 shows the computational molecule for the calculation of the wave height.

\section{Boundary conditions}

To obtain the wave propagation at open boundaries, we utilize the Snell's law, which permits that the waves leave the domain without modifying their direction or magnitude. The obstacles and buildings inside the domain are considered wall boundaries with a reflection factor $\left(K_{L}\right)$, ranging from 0.0 (no reflection) to 1.0 (completely reflected).

To calculate the wave height at the borders of any breakwater, we formulate two expressions:

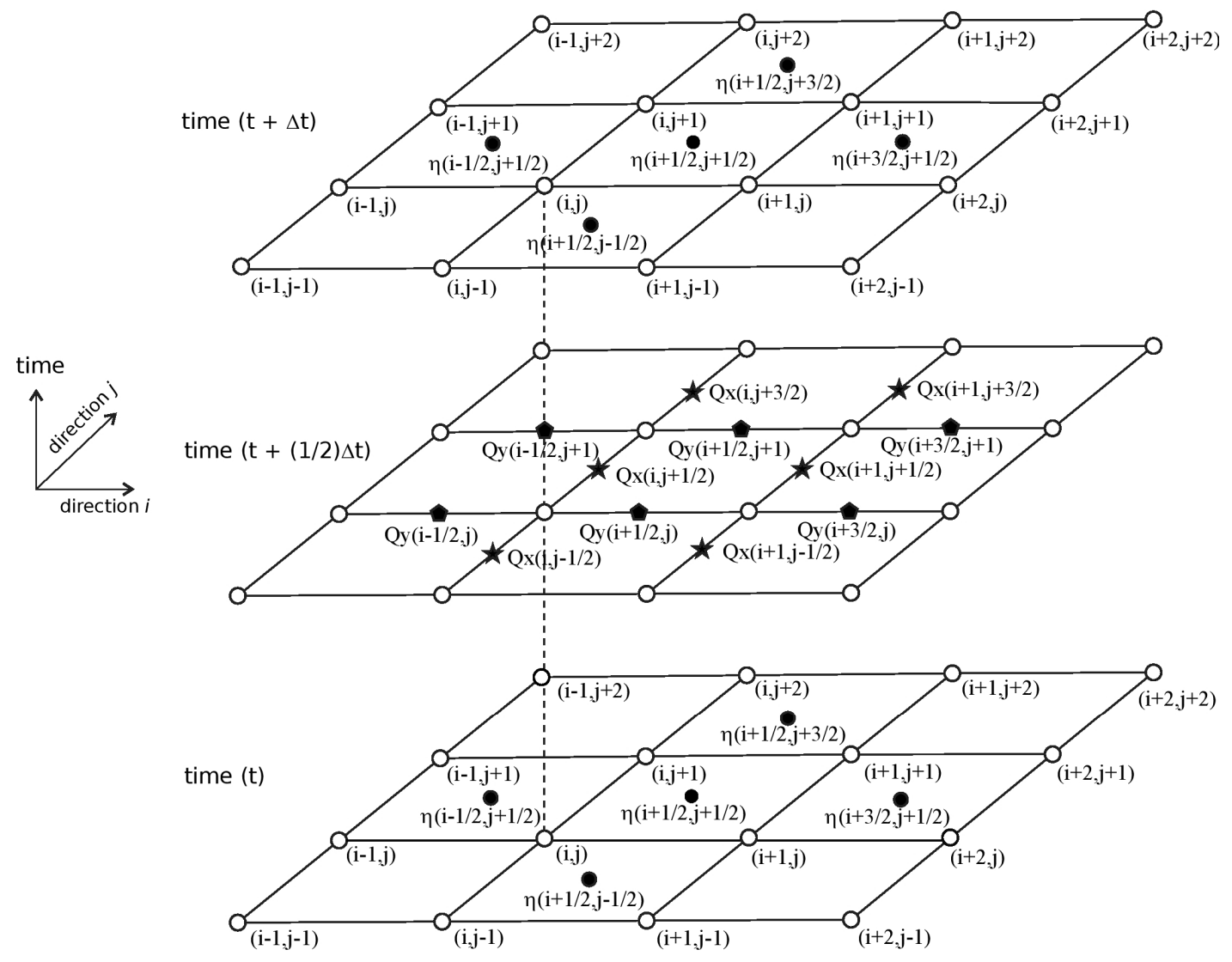

Figure 4. Computational domain for the calculation of the wave heights. 


$$
\begin{aligned}
& \eta_{0}^{n+1}=\left(1+K_{L}\right) \times \eta_{\left(\frac{C \Delta t}{\Delta x}\right)}^{n}-K_{L} \eta_{0}^{n-1} \\
& \eta_{L}^{n+1}=\left(1+K_{L}\right) \times \eta_{\left(L-\frac{C \Delta t}{\Delta x}\right)}^{n}-K_{L} \eta_{0}^{n-1}
\end{aligned}
$$

The Eq. (9) is used at the start of the breakwater of any length and the Eq. (10) is used at the end. The Figure 5 shows how the boundary conditions are applied.

For the wave height of the quasi-oscillating waves produced by the shock of the incident waves of height $\left(H_{i}\right)$ versus the reflecting waves of height ( $H_{r}$ ) the new wave height could be estimated as:

where $K x$ is the factor of group in $x, K y$ factor of group in $y, x$ is the distance with respect to $x$-axis and $y$ the distance with respect to $y$-axis.

At the vertical open boundaries, the proper condition for the Eq. (6) at $i=1$ and $i=n i$ along the line

$$
\left(y=j \times \Delta y+\frac{1}{2}\right) \text { is determined as: }
$$

$$
\begin{aligned}
& \eta_{i, j}^{n+1}=\frac{H_{i, j}}{2} \cos \left[\left(K x_{i, j} X_{i} \cos \left(\theta_{i, j}\right)\right)+\left(K y_{i, j} Y_{j} \sin \left(\theta_{i, j}\right)\right)-\frac{2 \pi}{T} \times t\right] \\
& Q x_{1, j+\frac{1}{2}}^{t+1}=Q x_{1, j+\frac{1}{2}}^{t}-\frac{C_{1, j+\frac{1}{2}}^{2} \Delta t}{\Delta x}\left(\eta_{\frac{5}{2}, j+\frac{1}{2}}^{t}-\eta_{\frac{3}{2}, j+\frac{1}{2}}^{t}\right) \\
& Q x_{n i, j+\frac{1}{2}}^{t+1}=Q x_{n i, j+\frac{1}{2}}^{t}-\frac{C_{n i, j+\frac{1}{2}}^{2} \Delta t}{\Delta x}\left(\eta_{n i, j+\frac{1}{2}}^{t}-\eta_{n i-1, j+\frac{1}{2}}^{t}\right)
\end{aligned}
$$

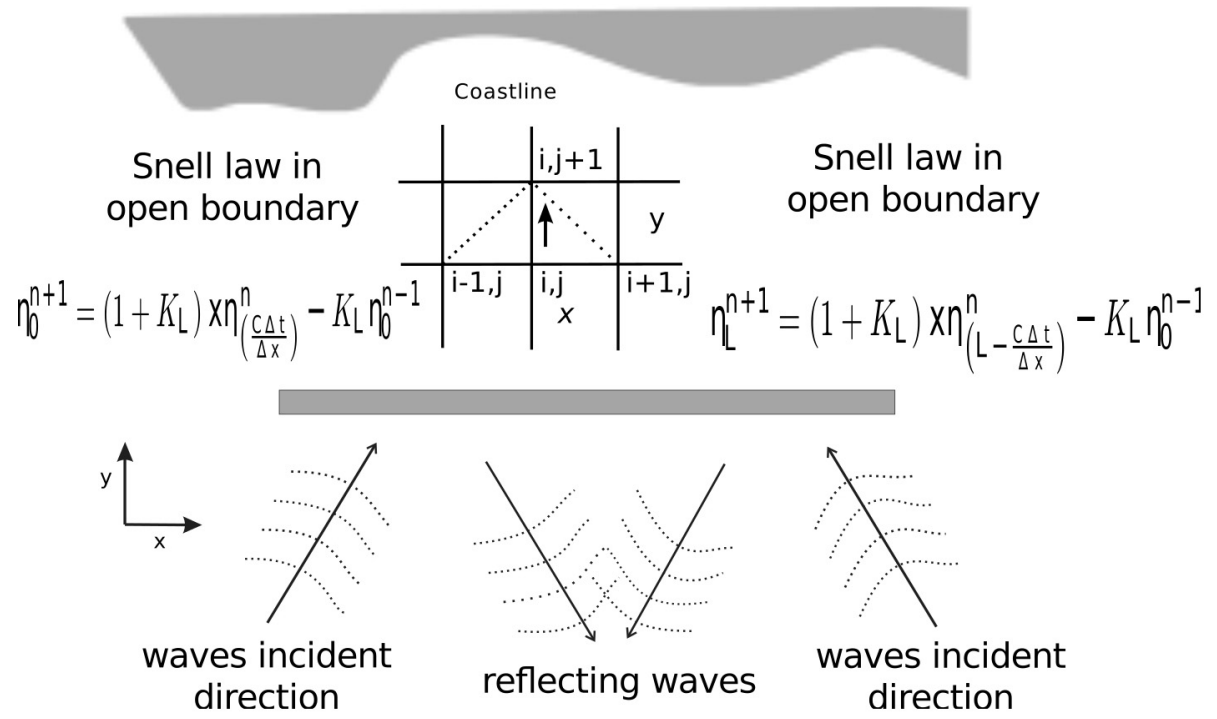

Figure 5. Boundary conditions used in the open domain and near of the breakwater. 
Analogous, for the horizontal open boundary the Eq. (7) at $j=1$ and $j=n j$ along the line $\left(x=i \times \Delta x+\frac{1}{2}\right)$, are used the next equations:

$Q x_{1, j+\frac{1}{2}}^{t+1}=Q x_{1, j+\frac{1}{2}}^{t}-\frac{C_{1, j+\frac{1}{2}}^{2} \Delta t}{\Delta x}\left(\eta_{\frac{5}{2}, j+\frac{1}{2}}^{t}-\eta_{\frac{3}{2}, j+\frac{1}{2}}^{t}\right)$

$Q y_{i+\frac{1}{2}, n j}^{t+1}=Q y_{i+\frac{1}{2}, n j}^{t}-\frac{C_{i+\frac{1}{2}, n j}^{2} \Delta t}{\Delta y}\left(\eta_{i+\frac{1}{2}, n j}^{t}-\eta_{i+\frac{1}{2}, n j-1}^{t}\right)$

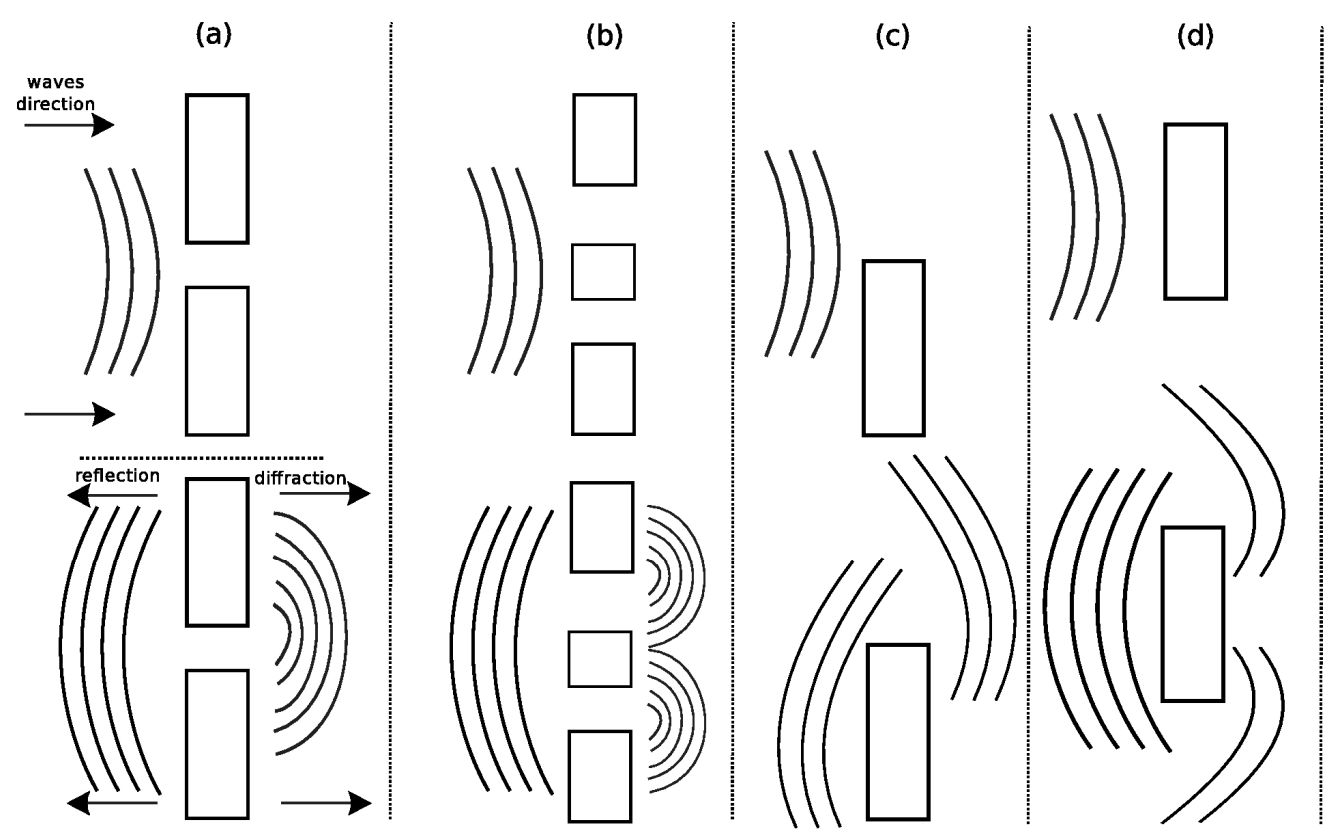

Figure 6. Diffraction-Reflection diagram produced by different configurations of breakwaters.
Finally, the angle frequency could be estimated by the relation between the phases $Q x$ and $Q y$ as:

$$
\omega=\tan ^{-1}\left(\frac{Q y^{n+1}}{Q x^{n+1}}\right)
$$

\section{Validation of the model}

To carry out the validation of the numerical code, theoretical examples were used in order to compare the results produced by the effects of refraction, diffraction and reflection. In our examples we want to reproduce the diffraction and reflection caused by the presence of one, two or three symmetrical break waters with different openings.

The Figure 6 depicts the geometry of different configuration of breakwaters and the expected waves diagram at the exit of the openings. 
In the Figure 7 we can see the effects of diffraction and reflection over different breakwaters setup, where the behavior of the waves agrees with the expected solution depicted in the Figure 6 . The size of each grid cell is $\Delta x=\Delta y=10 \mathrm{~m}$ and the time step $\Delta \mathrm{t}$ is of $1 \mathrm{~s}$, the grid size is of $110 \times 110$, in the in- cise (a) the breakwaters are located in the middle of the grid with an opening of $10 \mathrm{~m}$, in the incise $(b)$ are depicted three breakwaters with two openings of $10 \mathrm{~m}$, in the incise $(c)$, the breakwater is in the middle-right and finally in the incise $(d)$ the breakwater is in the middle of the domain.

In our next example we model the wave transformation produced by the breakwaters of a small rectangular harbor, depicted in the Figure 8, the experimental solution (reference solution) for this problem was presented by Unluate [25] and a numerical solution by Lee[11] and Maa [15].

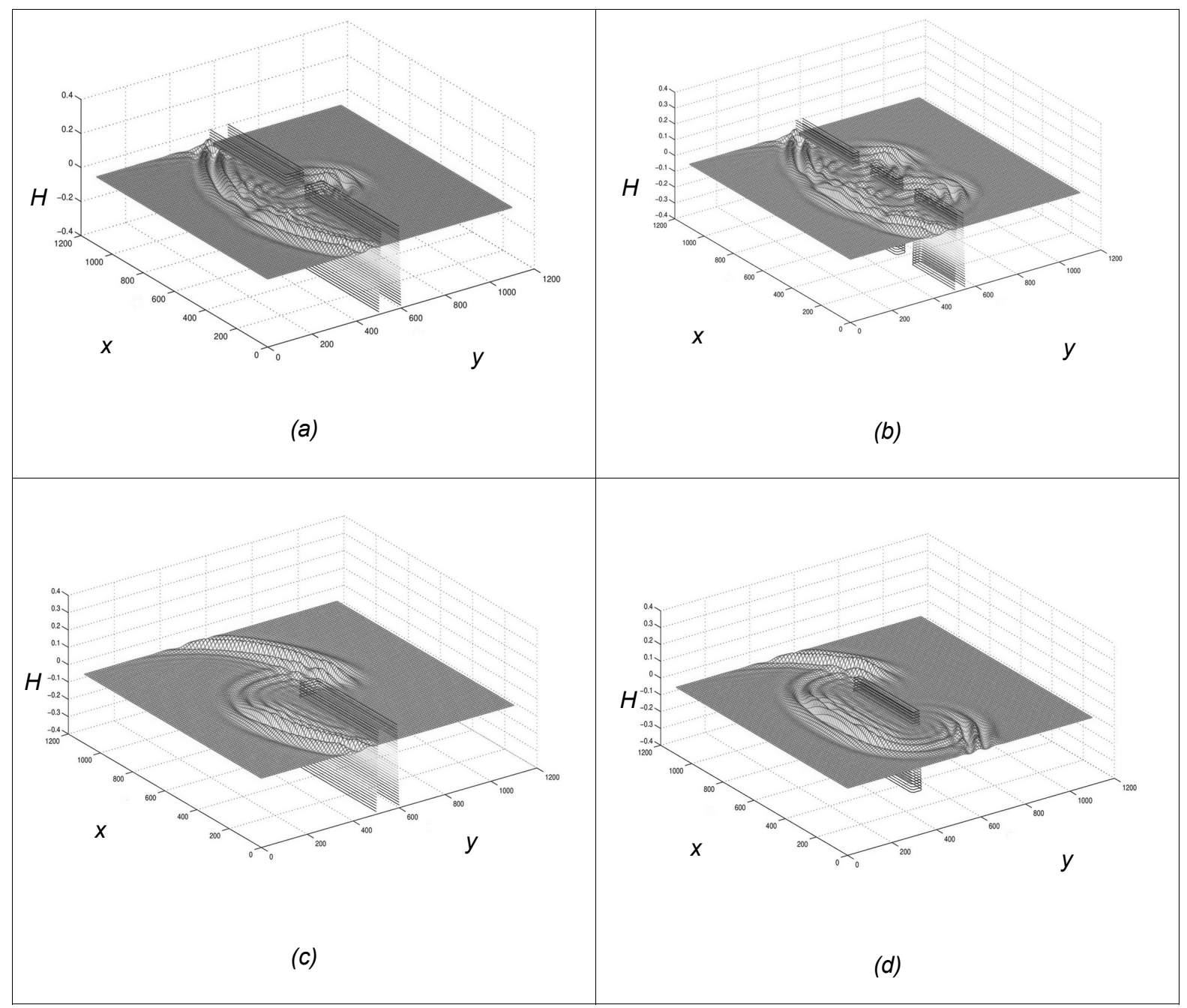

Figure 7. Snapshots of the normalized wave height with different breakwaters configurations, reproduced with the numerical model. 


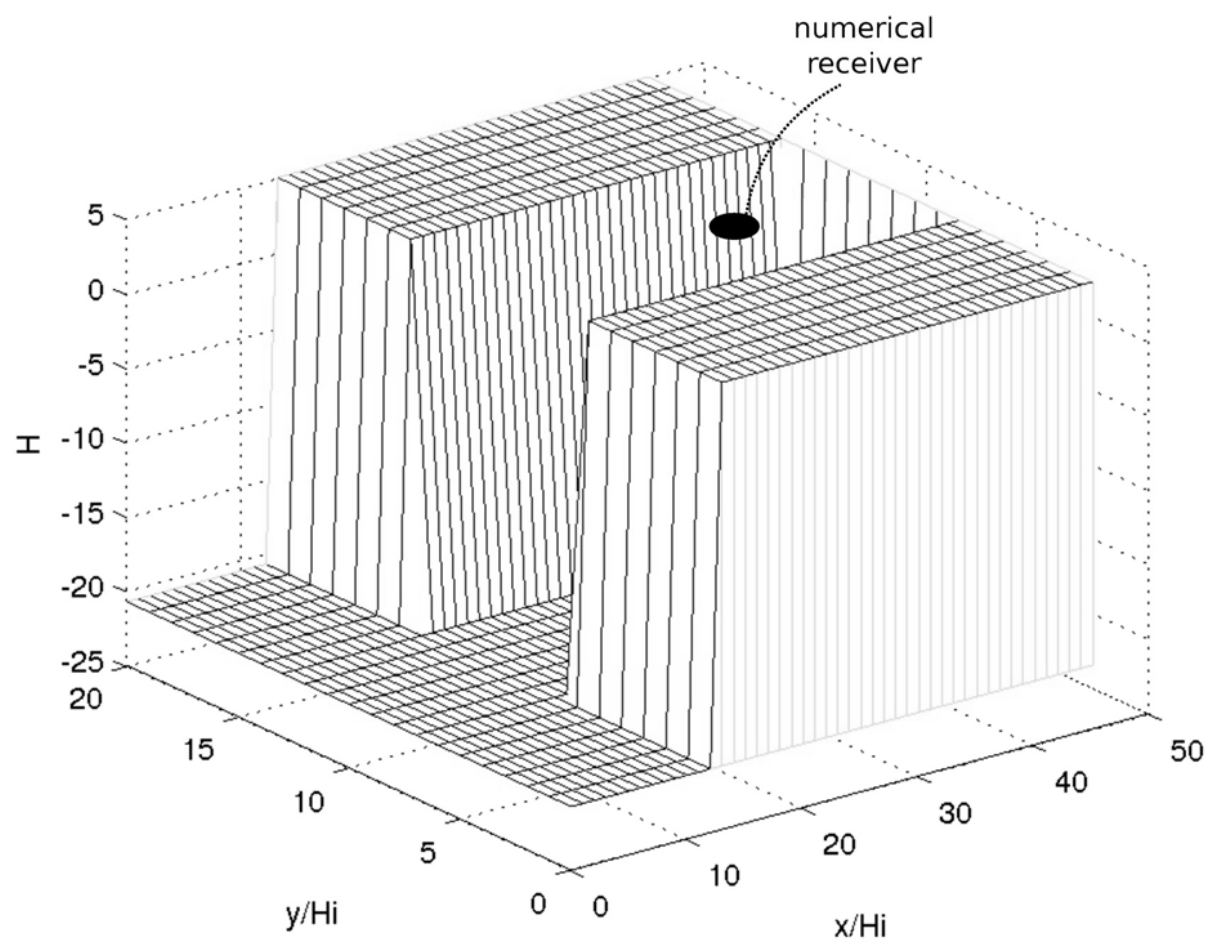

Figure 8. Small harbor geometry.

The mini experimental harbor geometry is of $0.3212 \mathrm{~m}$ in length $\times 0.0605 \mathrm{~m}$ of wide and 0.2576 $\mathrm{m}$ of depth, the angle of incident of the waves is zero degrees and the initial wave height is $0.01 \mathrm{~m}$, the initial parameters summary of the numerical test are depicted in the Table 1.

\begin{tabular}{|ll|}
\hline Parameter & Value \\
\hline $\mathrm{H}(\mathrm{m})$ & 0.01 \\
$\mathrm{~T}(\mathrm{~s})$ & $1 \Delta \mathrm{t}$ \\
$\theta($ degrees $)$ & 0.00 \\
$\mathrm{~h}(\mathrm{~m})$ & 0.2576 \\
$\Delta \mathrm{x}(\mathrm{m})$ & 0.10 \\
$\Delta \mathrm{y}(\mathrm{m})$ & 0.10 \\
$\mathrm{~W} \times \mathrm{L}(\mathrm{m})$ & $4.497 \times 1.845$ \\
$\mathrm{MP} \times \mathrm{NP}$ & $45 \times 20$ \\
Computing time (s) & 41 \\
\hline
\end{tabular}

$\mathrm{W}, \mathrm{L}$ are the width and height of the study domain MP,NP are the number of cell in the direction $x$ and $y$ respectively

Table 1. Parameters used for the coastal area of the LVNPP
The Figure 9 shows the contour of the wave height obtained with the numerical code developed when the waves are stable; the boundary condition at the wall was considered with a reflection coefficient of 1.0 that means a total reflecting wall.

Later a quantitative comparison between the solutions obtained by Unluate [25] and Maa [15] was made. The Figure 10 shows normalized wave height obtained at the receiver compared with the reference solution and the numerical solution obtained by Maa with a max relative error of $0.75 \%$, the technique used to approximate the error could be seen in [16].

\section{Numerical experiments in the breakwater of the LVNPP}

The numerical simulation was carried out in the coastal area of the LVNPP. It is the only electric power generating nuclear plant in Mexico and produces about $4.5 \%$ of the country's electrical energy. LVNPP has an original installed capacity of 1,365 Megawatts (Mw). It consists of two units 


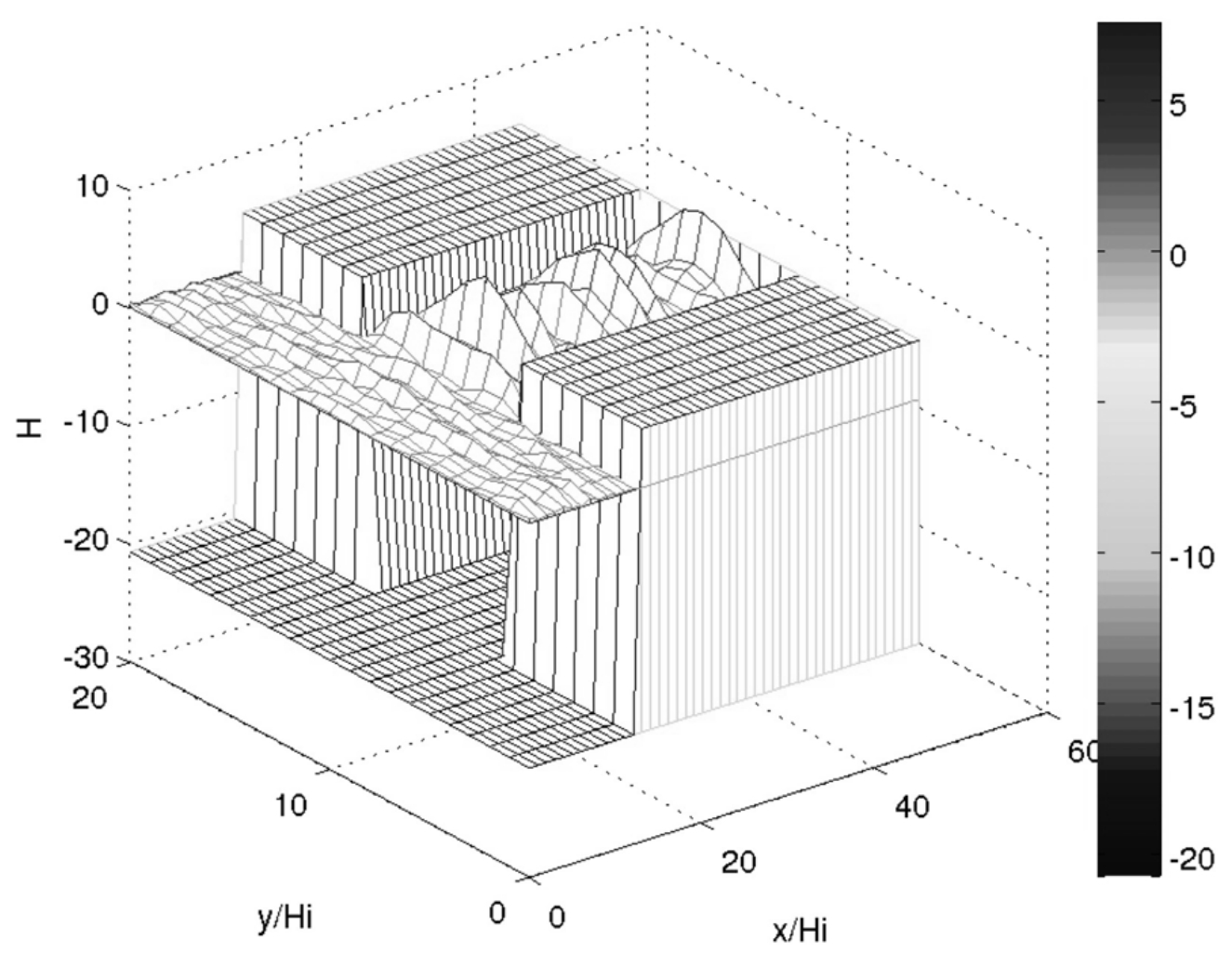

Figure 9. Relative wave height distribution into the small harbor.

General Electric Boiling Water Reactors (BWR-5) using Uranium (U235 Isotope $3 \%$ enriched) as fuel. Unit-1 (U-1) started its operation on July 29th, 1990. Unit-2 (U-2) started its operation on April 10th, 1995. The plant is owned and operated by the national electric company of the Mexican government (see Figure 11).

The generation of electric power at the plant is based on the technology of nuclear fission of uranium atoms, which takes place in the reactor. The energy released by the nuclear fission is transferred as heat from the fuel to the cooling water, which boils into steam. The water discharge of the cooling system is carried out in a trough channel with a flow rate of $63 \mathrm{~m}^{3} / \mathrm{s}$ and a mean speed of $1.4 \mathrm{~m} / \mathrm{s}$.

The type of the cooling system is considered open and actually the intake of the water is superficial, the breakwater which protects the intake have two piers, and the main problem is the blockage and the recirculation of hot water has caused deficiencies in the cooling system.

The grid of the study domain is shown in the Figure 12 , it is conformed by 5,896 cells with a constant size of $\Delta x=\Delta y=250 \mathrm{~m}$. The initial parameters for this simulation are defined in the Table 2. 


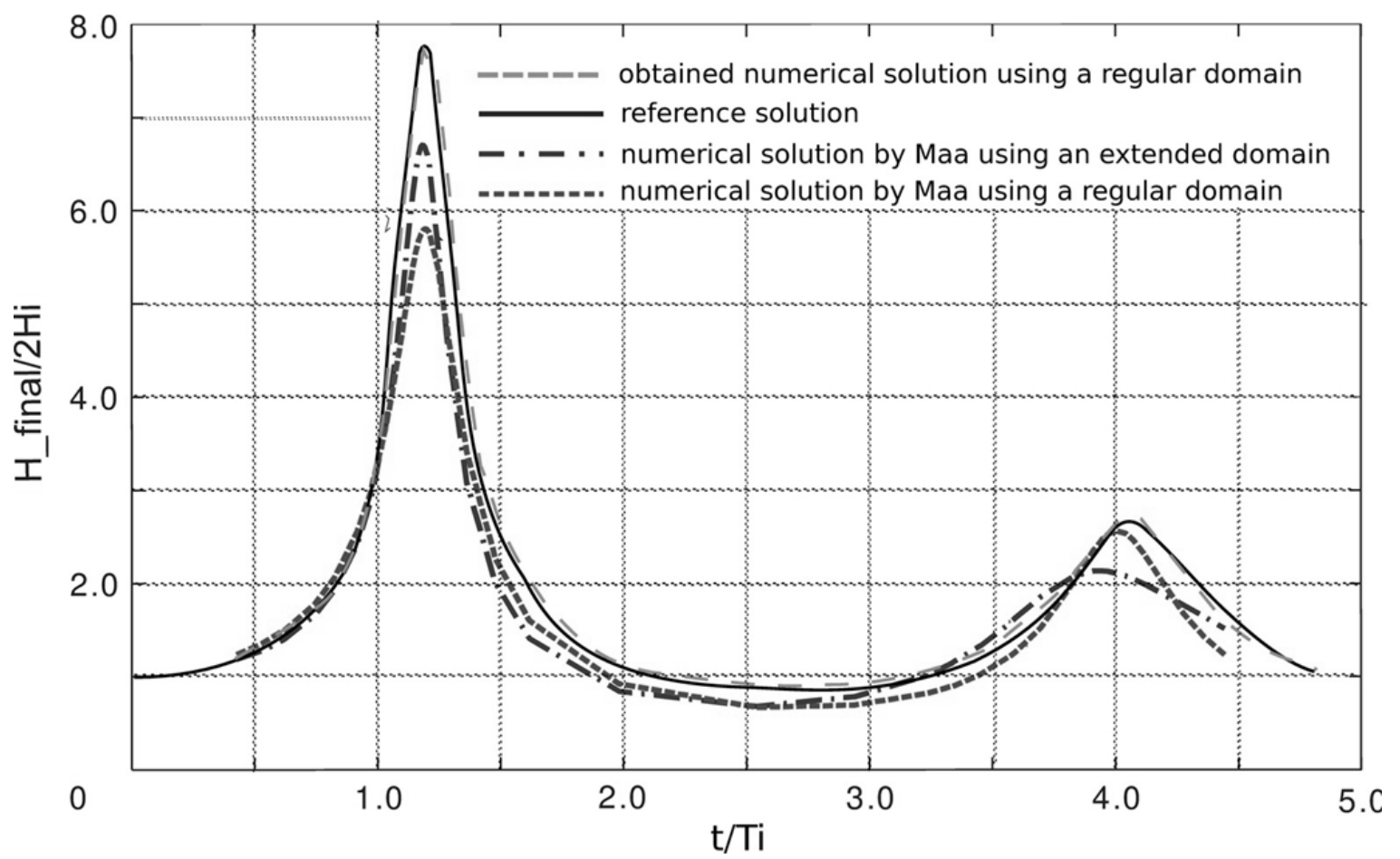

Figure 10. Time evolution of the wave height at the numerical receiver.
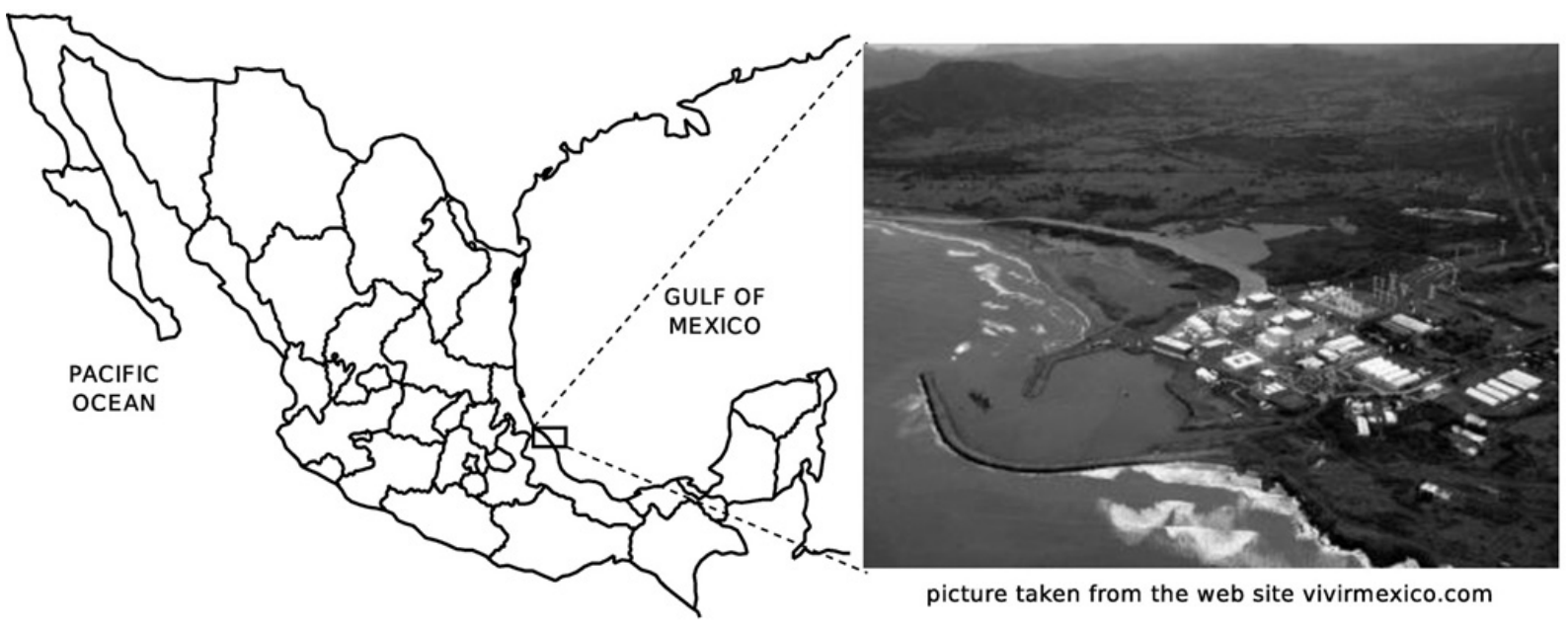

picture taken from the web site vivirmexico.com

Figure 11. Location map of the study area and the protection structures coordinates $19^{\circ} 43^{\prime} 06.67^{\prime \prime} \mathrm{N} 96^{\circ} 24^{\prime} 04: 96^{\prime \prime} \mathrm{W}$. 


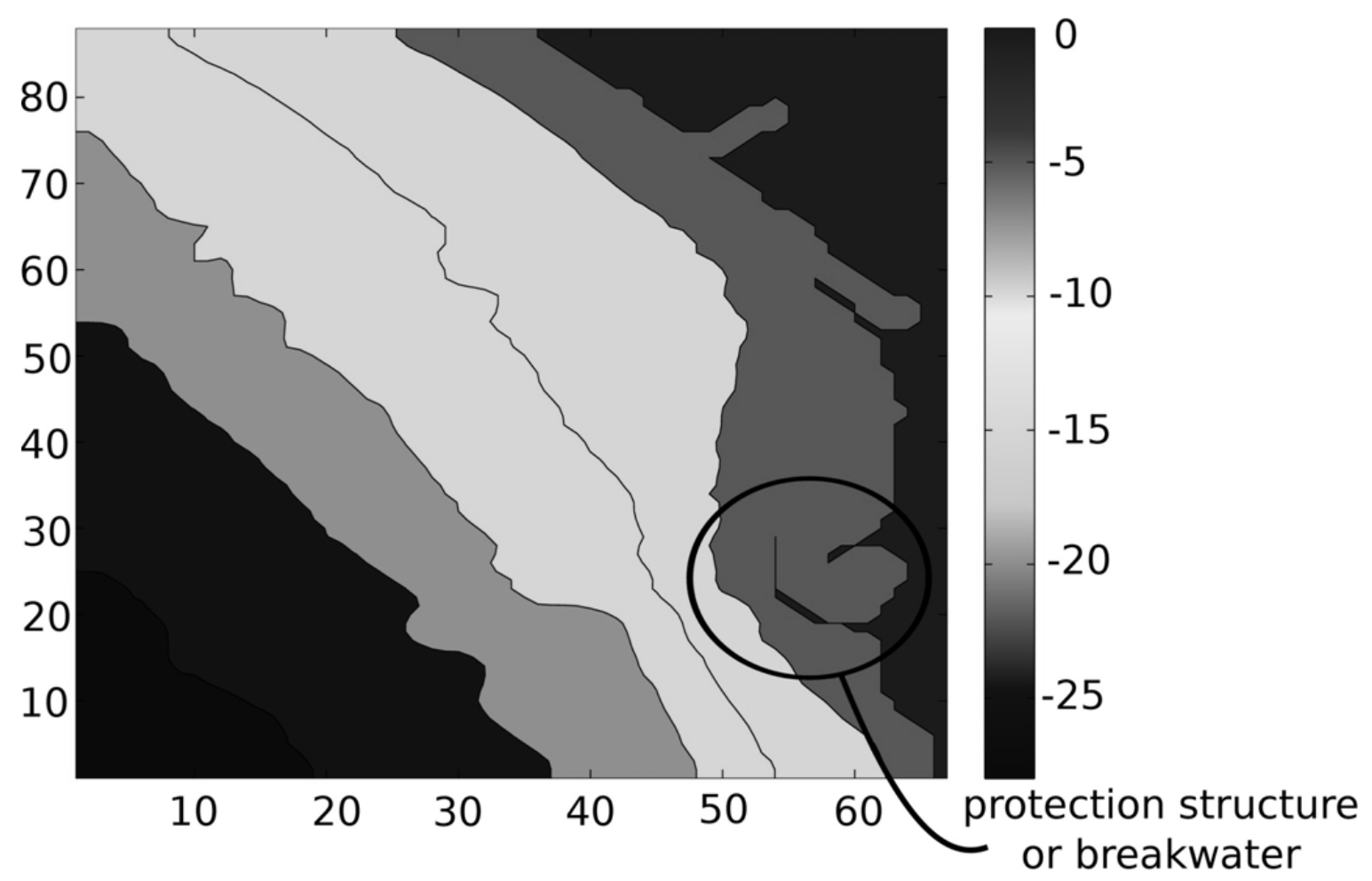

Figure 12. Bottom topography contour (LVNPP).

\begin{tabular}{|ll|}
\hline Parameter & Value \\
\hline $\mathrm{H}(\mathrm{m})$ & Bottom topography \\
$\mathrm{T}(\mathrm{s})$ & $1 \Delta \mathrm{t}$ \\
$\theta($ degrees $)$ & $82.07 \mathrm{NE}$ \\
$\mathrm{h}(\mathrm{m})$ & $1.35 \mathrm{~m}$ \\
$\Delta \mathrm{x}(\mathrm{m})$ & 250 \\
$\Delta \mathrm{y}(\mathrm{m})$ & 250 \\
$\mathrm{~W} \times \mathrm{L}(\mathrm{m})$ & $22 \mathrm{~km} \times 16.75 \mathrm{~km}$ \\
MP $\times \mathrm{NP}$ & $88 \times 67$ \\
Computing time $(\mathrm{s})$ & $160 \mathrm{~s}$ \\
\hline
\end{tabular}

$\mathrm{W}, \mathrm{L}$ are the width and height of the study domain MP,NP are the number of cell in the direction $x$ and $y$ respectively

Table 2. Parameters used for the coastal area of the LVNPP. 
In the Figure 13 is shown the result for the coastal area, we can see the refraction effects when the waves are near the coastline produced by the bottom topography.

Due to the importance of the protection structure area is necessary to make a refinement of the grid within the breakwater, this refinement is make with 600 cells with a size of $\Delta x=\Delta y=5 \mathrm{~m}$. In the Figure 14 is shown the bathymetry of the breakwater area.
To verify the model, as first step, is proposed a breakwater geometrically idealized (see Figure 15), this mean a controlled scenario to represent the wave transformations into the breakwater. This idealized breakwater is very close to the way and localization of the real breakwater to observe the behavior of wave propagation.

The results of the wave propagation are shown in the Figure 16 for different simulation times, we can see that the diffraction and reflection phenomena are diminished by the breakwater structure.

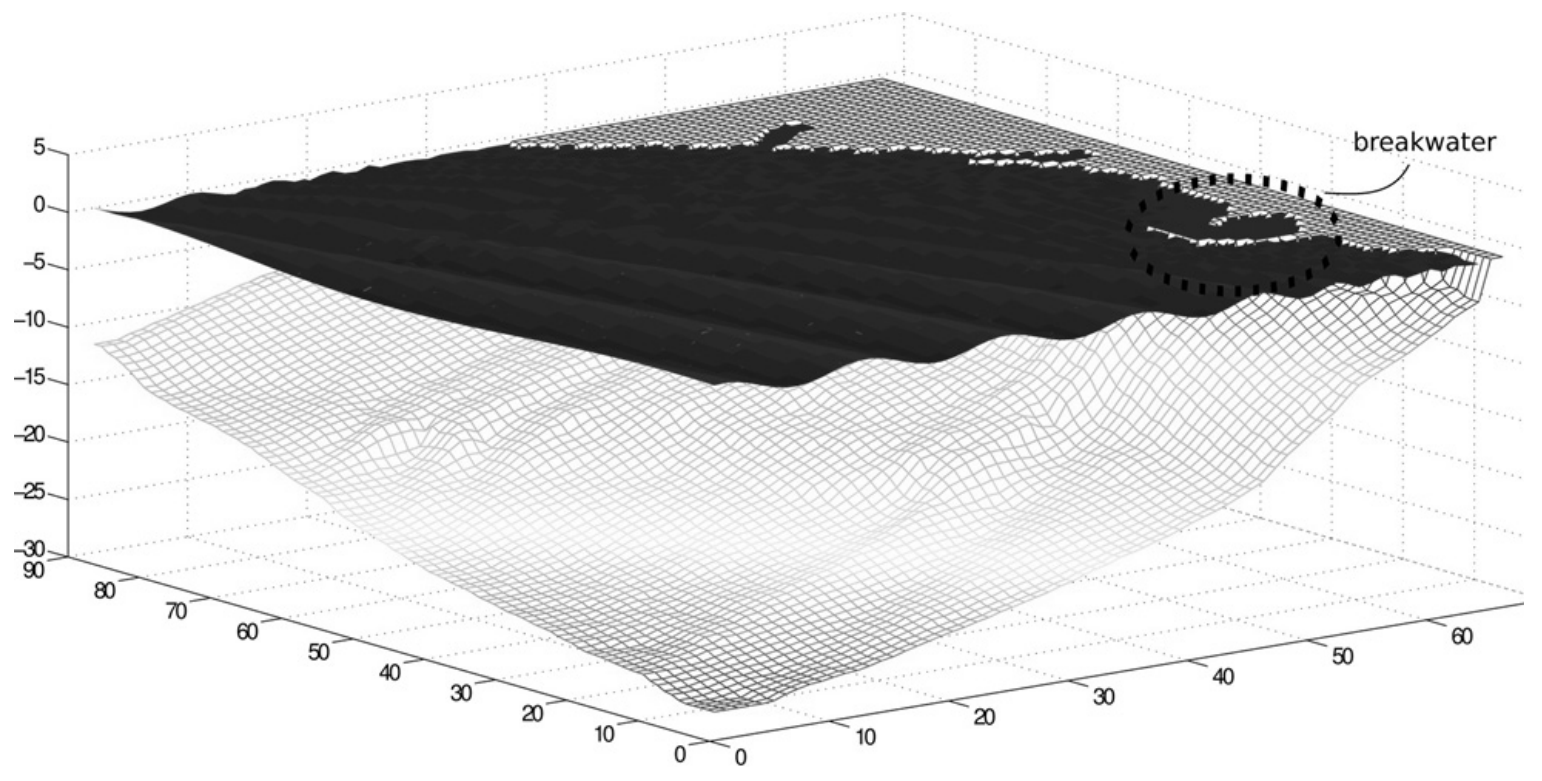

Figure 13. Wave height distribution in the coastal zone (LVNPP). 


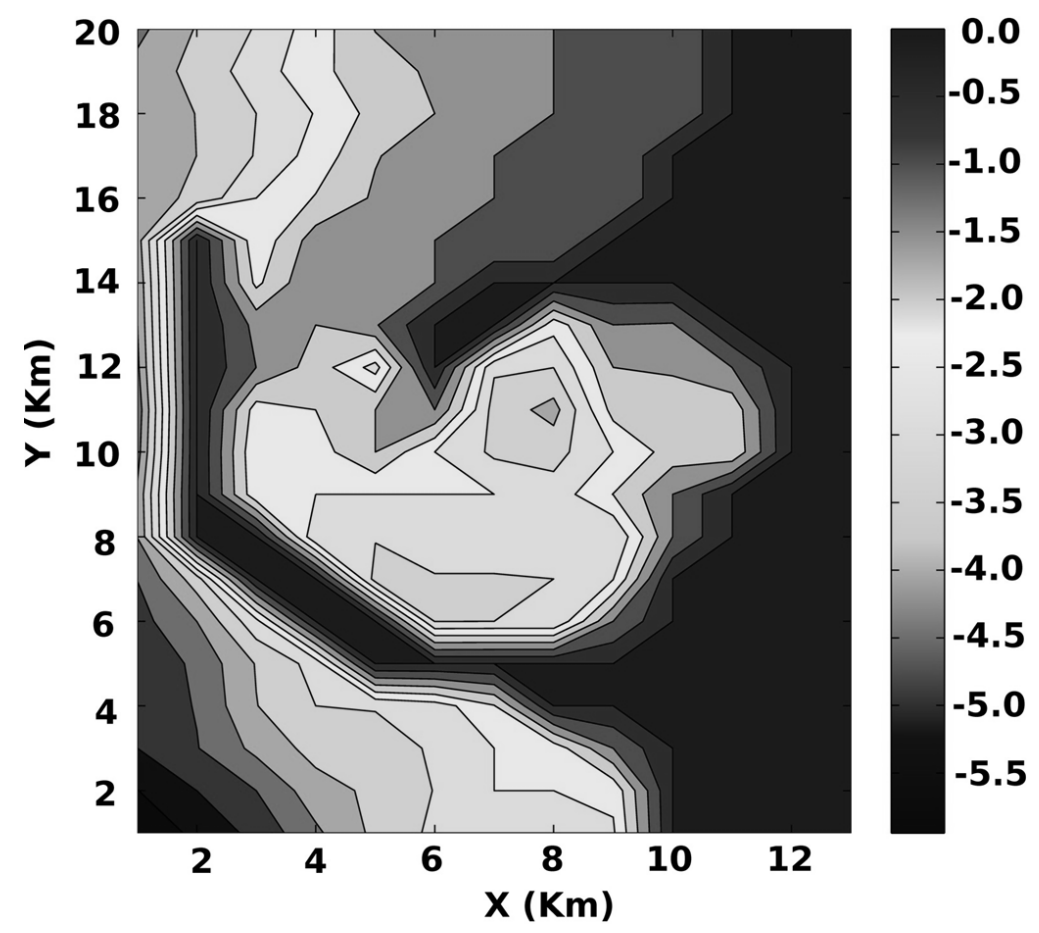

Figure 14. Bottom topography contour of the breakwater area.

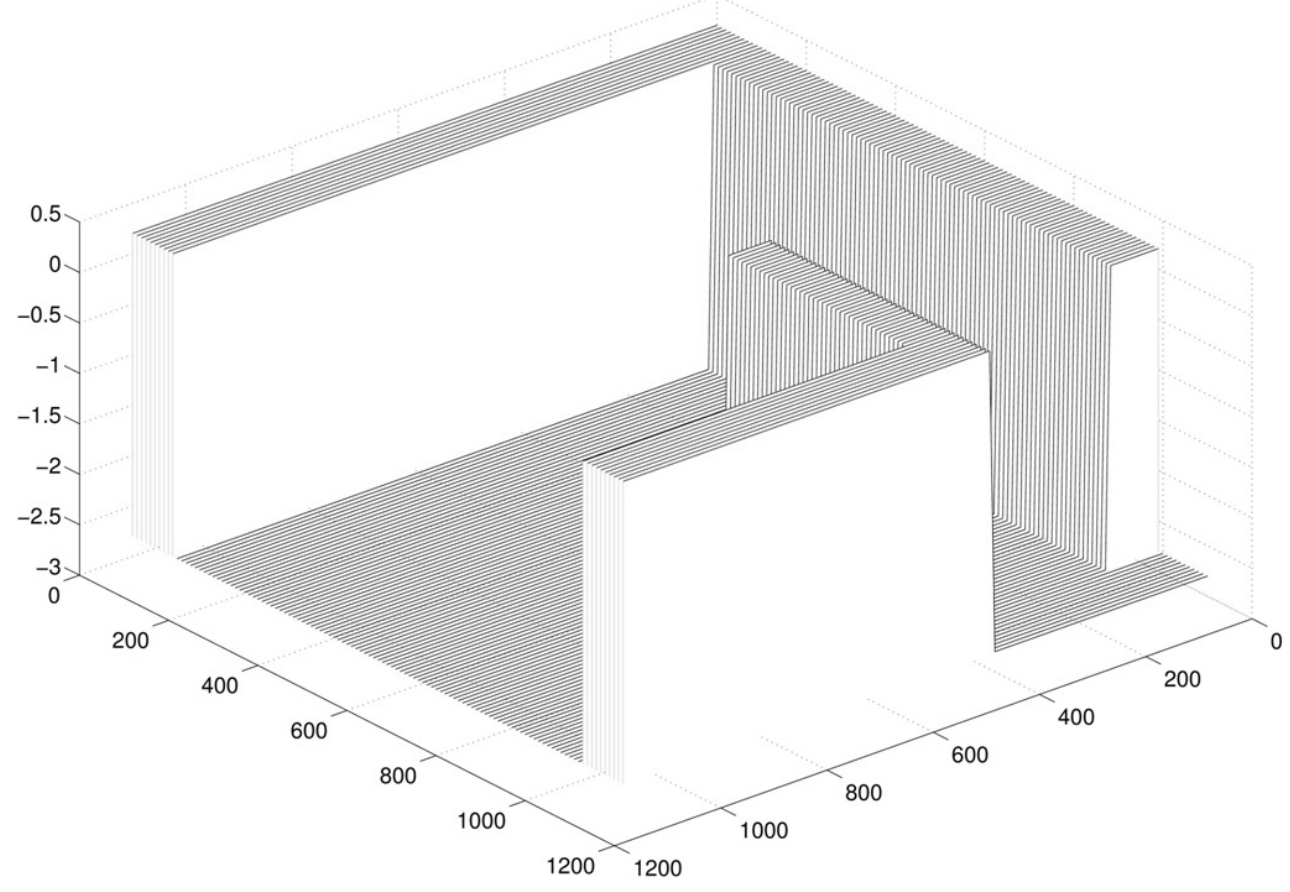

Figure 15 . Geometry of the idealized breakwater. 


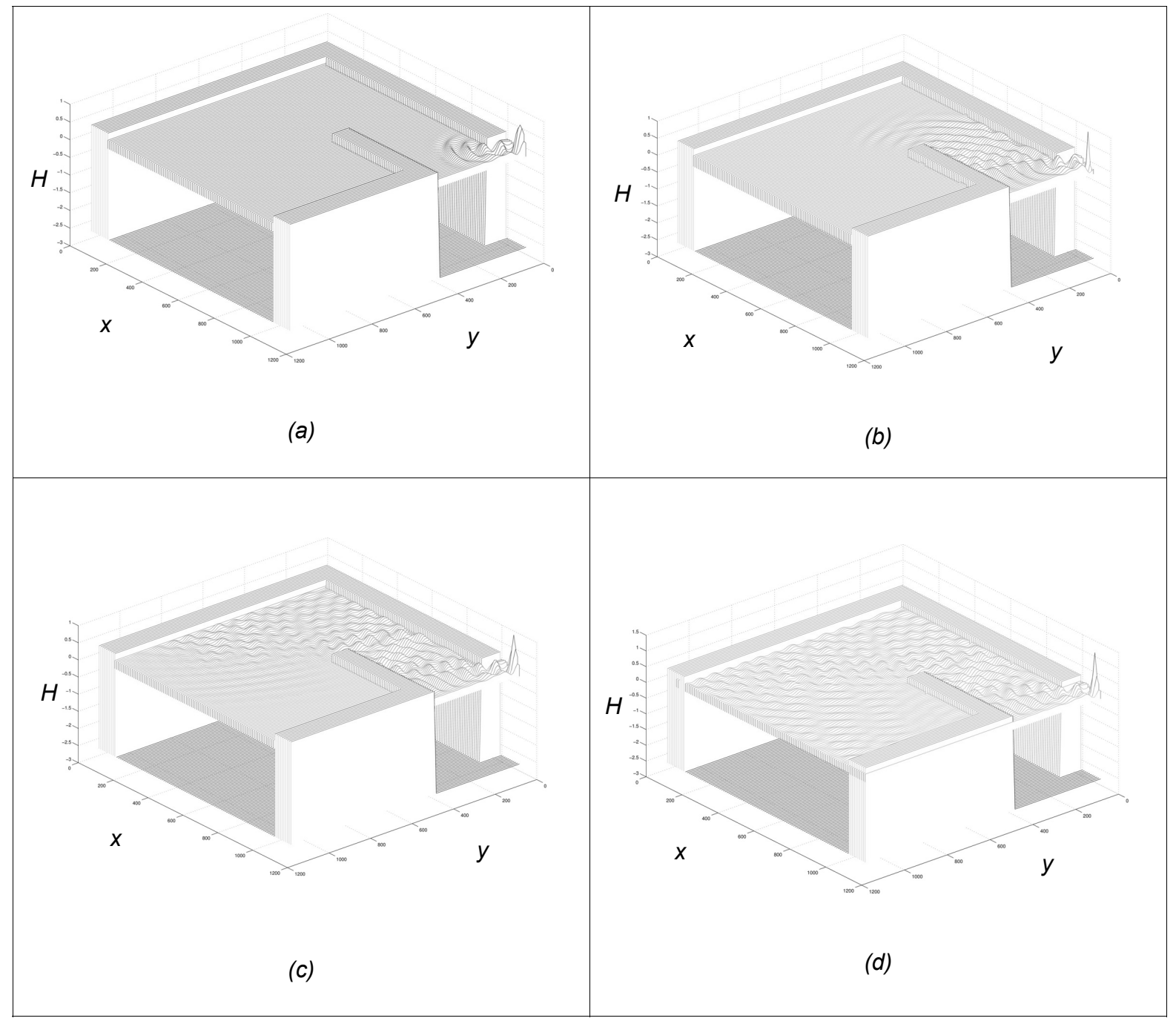

Figure 16. Snapshots of the wave height distribution into the breakwater idealized at $16 \mathrm{~s}(\mathrm{a}), 34 \mathrm{~s}(\mathrm{~b}), 50 \mathrm{~s}$ (c) and $64 \mathrm{~s}(\mathrm{~d})$ of simulation.

Once the simulations over the idealized breakwater were done and shown results with patterns well defined, we carry out numerical experiment with the real bathymetry and the real breakwater form. The simulation result of the stable waves is depicted in the Figure 17. 


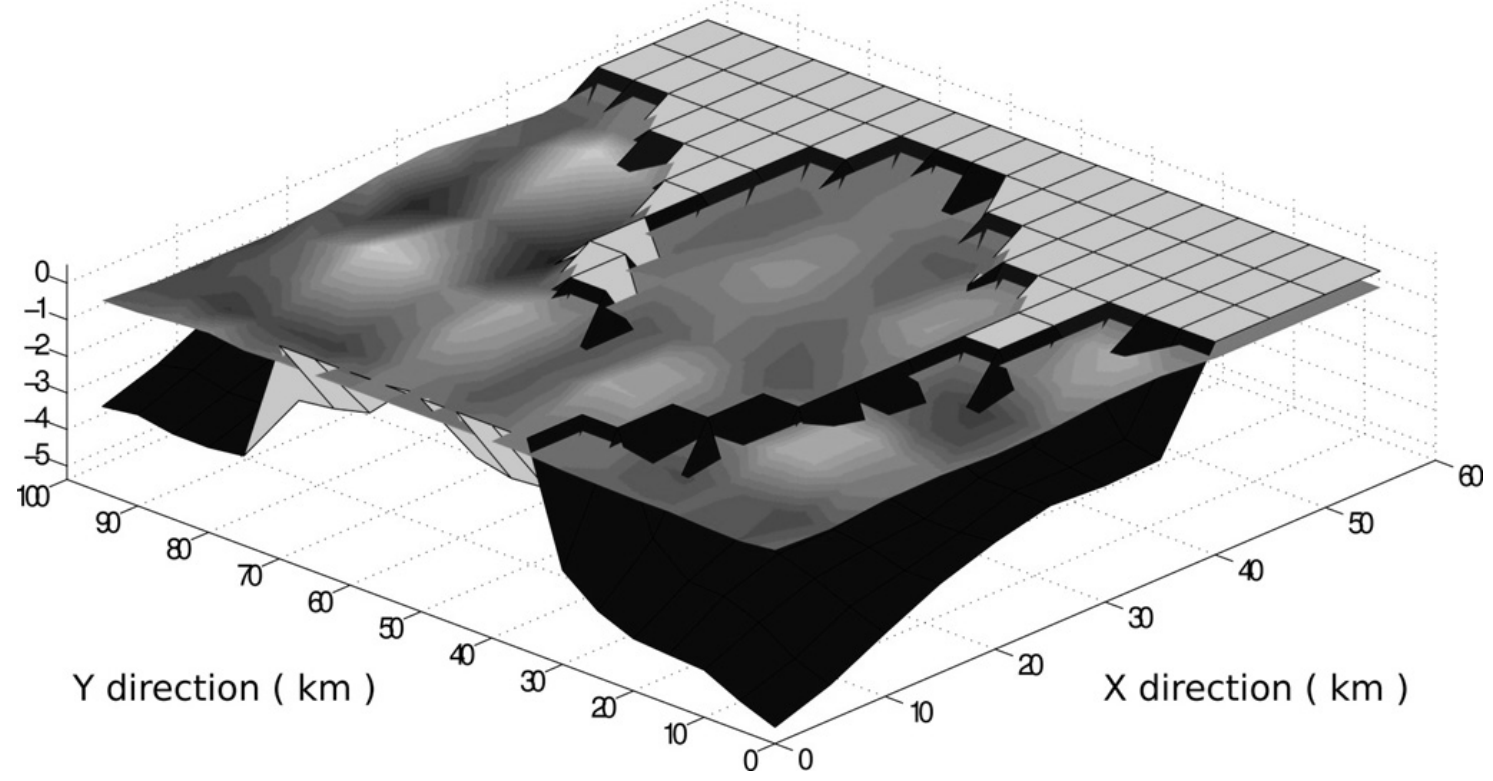

Figure 17. Stable wave height distribution into the breakwater (LVNPP).

In the Figure 18 we can see that the waves height into the breakwater is minimal, we find just a small disturbance in the free surface raging from 0.05 to
$0.1 \mathrm{~m}$, this pattern is consistent with the average data acquired in the meteorological stations.

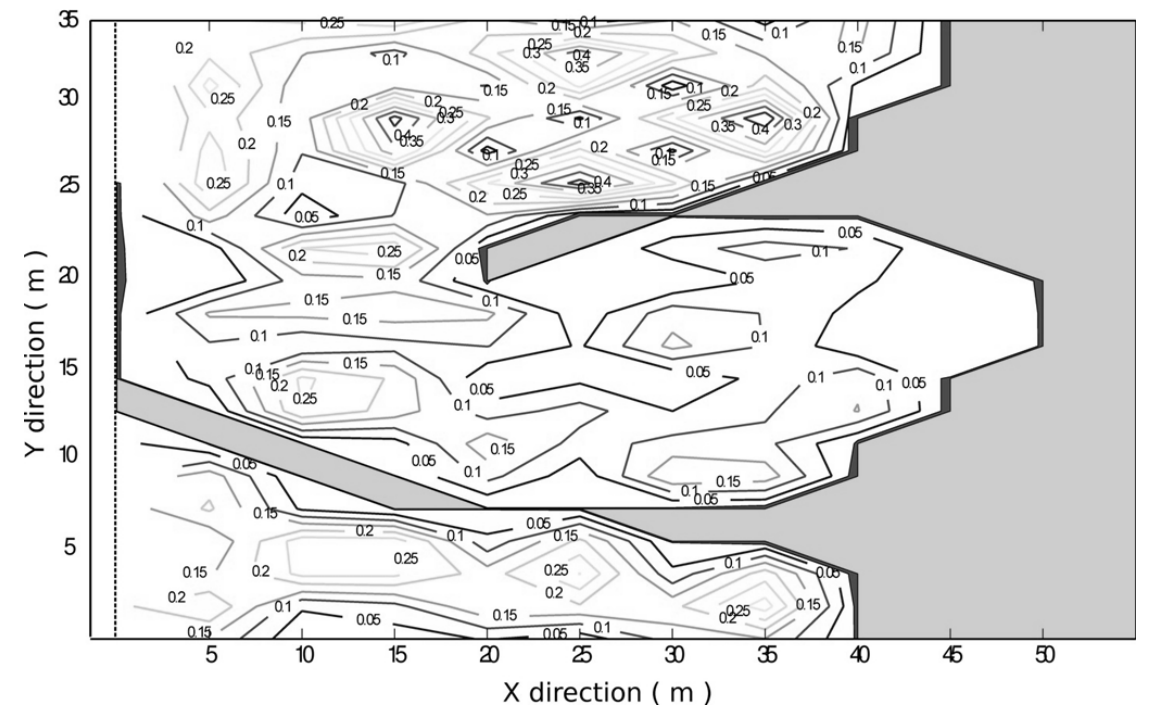

Figure 18. Stable wave heights contour distribution into the breakwater (LVNPP). 


\section{Numerical experiments in the nautical marine}

The nautical marine under study is located in the south of the state of Nayarit Mexico, municipality of Compostela in the town Los Ayala (see Figure 19).

The objective of the simulation is to modeling the wave transformation originated inside the protection building due to effects of incident wave with direction NW predominant in the zone. In order to monitor the wave heights that occur inside, ten numerical receivers were placed at some points inside and outside of the building. In the Figure 19 is depicted the location of the numerical receivers.

The data about the wave height, period and angle of incidence are shown in the table 3.

\begin{tabular}{|ll|}
\hline Parameters & Value \\
\hline $\mathrm{H}(\mathrm{m})$ & Bottom topography \\
$\mathrm{T}(\mathrm{s})$ & $8.5 \Delta \mathrm{t}$ \\
$\theta($ degrees $)$ & $68 \mathrm{NW}$ \\
$\mathrm{h}(\mathrm{m})$ & $1.73 \mathrm{~m}$ \\
$\Delta \mathrm{x}(\mathrm{m})$ & 5.0 \\
$\Delta \mathrm{y}(\mathrm{m})$ & 5.0 \\
$\mathrm{~W} \times \mathrm{L}(\mathrm{m})$ & $740 \mathrm{~m} \times 725 \mathrm{~m}$ \\
$\mathrm{MP} \times \mathrm{NP}$ & $148 \times 145$ \\
Computing time $(\mathrm{s})$ & $180 \mathrm{~s}$ \\
\hline
\end{tabular}

W, $L$ are the width and height of the study domain MP,NP are the number of cell in the direction $x$ and $y$ respectively

Table 3. Parameters used for the coastal area of the Nautical Marine

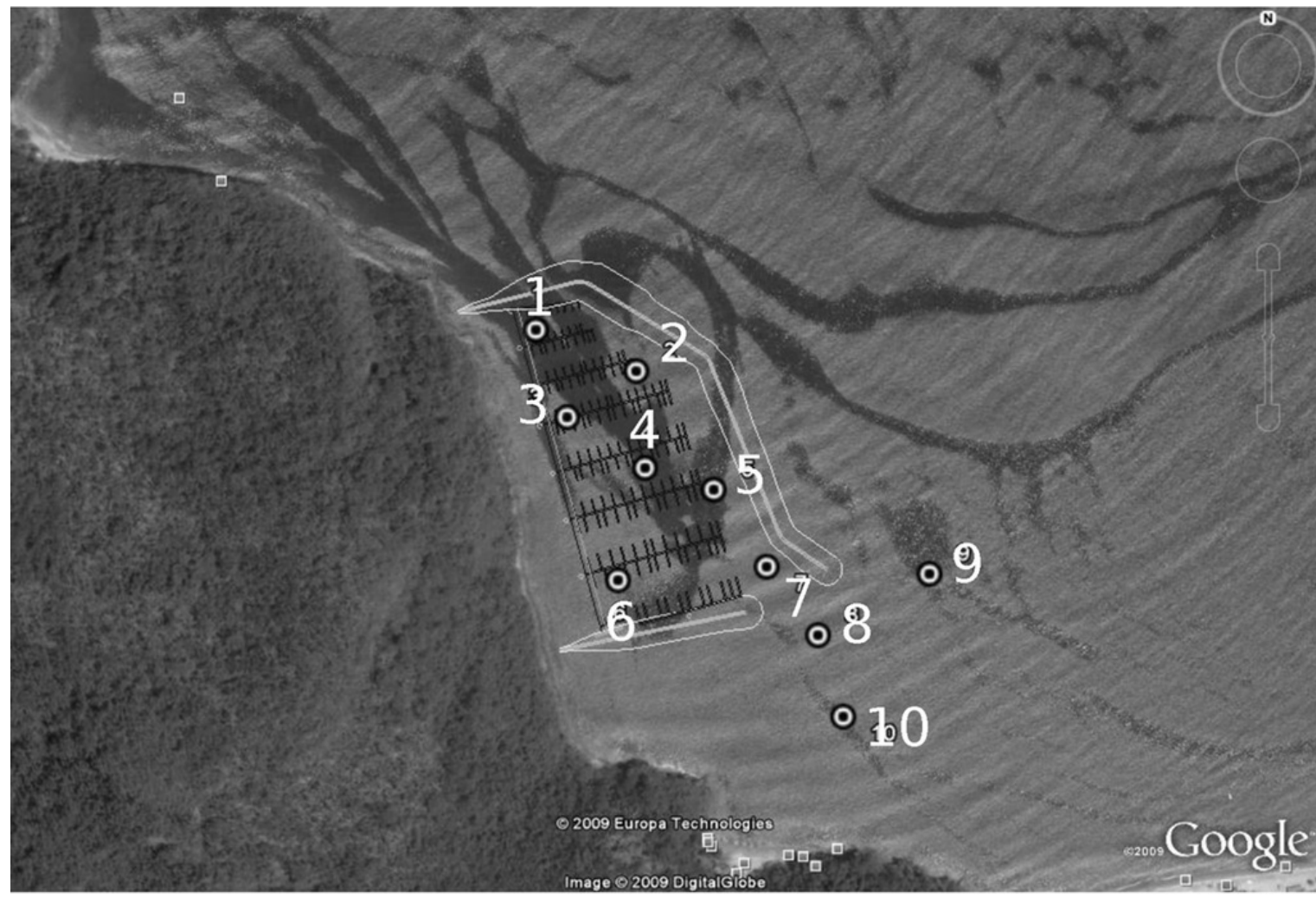

Figure 19. Location map of the nautical marine and the position of the numerical receivers, coordinates $21^{\circ} 01^{\prime} 46.83^{\prime \prime} \mathrm{N} 105^{\circ} 17^{\prime} 48.34^{\prime \prime} \mathrm{W}$. 
The mesh of the study domain is conformed by 21460 cells $(145 \times 148)$ with a constant size of $\Delta x=$ $\Delta y=5 \mathrm{~m}$ (see Figure 20).

In the Figure 21 we can see the different wave height inside the protection structure and in the Figure 22 the corresponding contour plot. We can see an average wave height of $10 \mathrm{~cm}$ and only in some points this height is exceeded but not exceeding 20 $\mathrm{cm}$, so the protection structure works as we expect.

The Figure 23 shows the waves height of the numerical receiver; in the graph we can observe the variations of waves height inside the nautical marine. At points 1 and 2 we can see relatively higher heights compared with the rest of the points produced by the reflexion effects, however do not represent any risk to navigation. Among the points 3 and 8 none is over $6 \mathrm{~cm}$ of height, thus the configuration of the protection structure satisfied the conditions of navigability in normal weather conditions. The points 9 and 10 show an increase in wave height, however these values do not exceed $15 \mathrm{~cm}$ and there is no risk in the entry to the nautical marine.

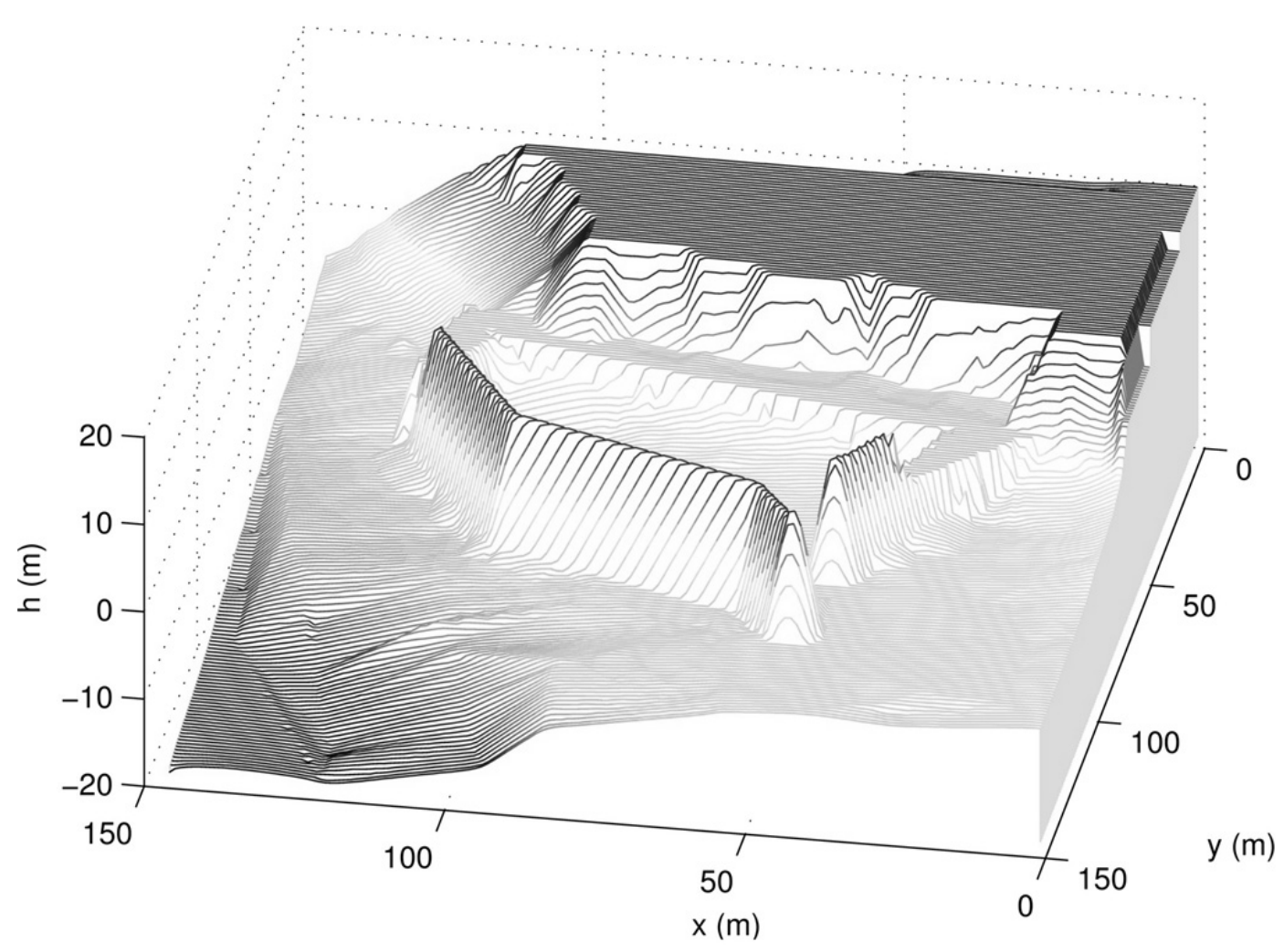

Figure 20. Bottom topography of the Nautical Marine area. 


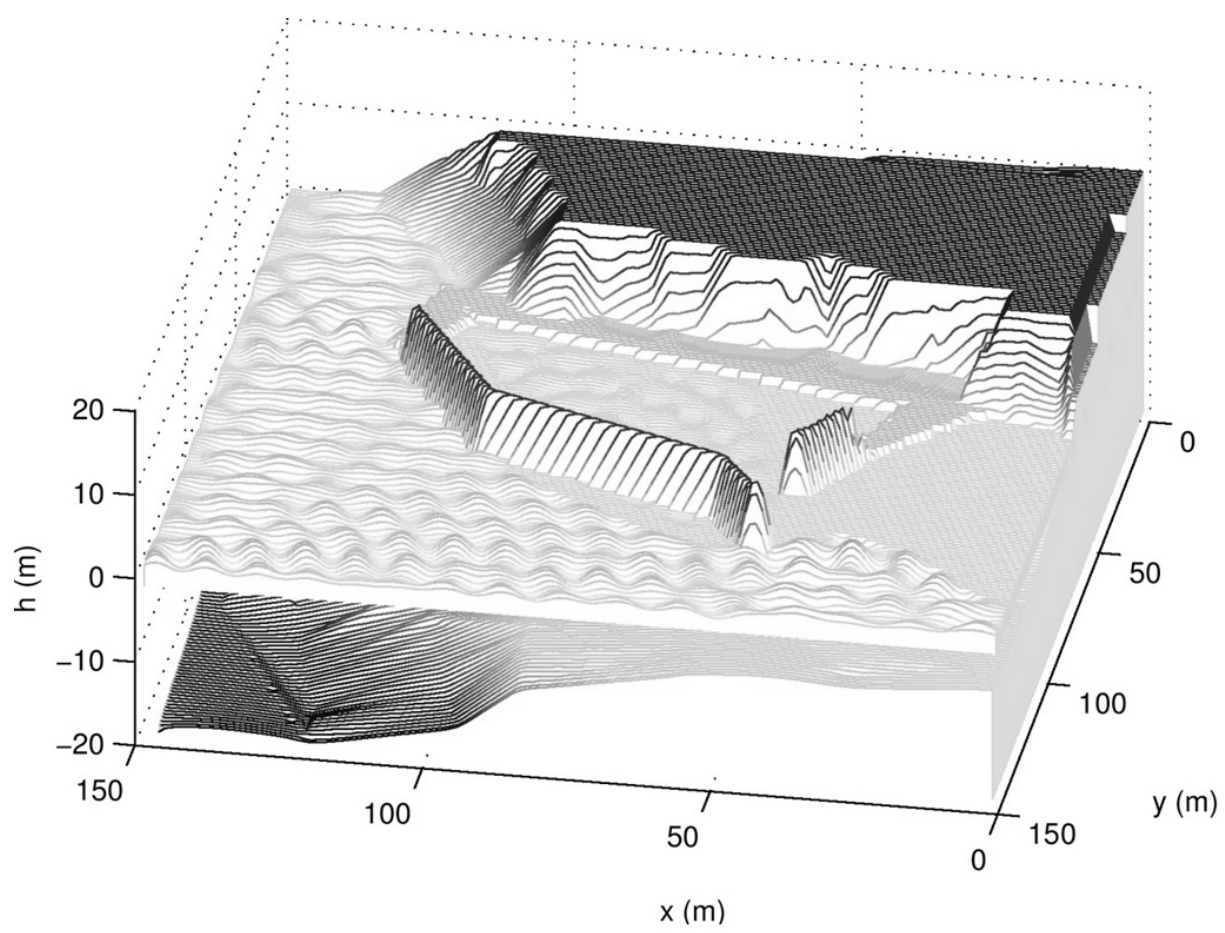

Figure 21. Stable wave height distribution into the nautical marine.

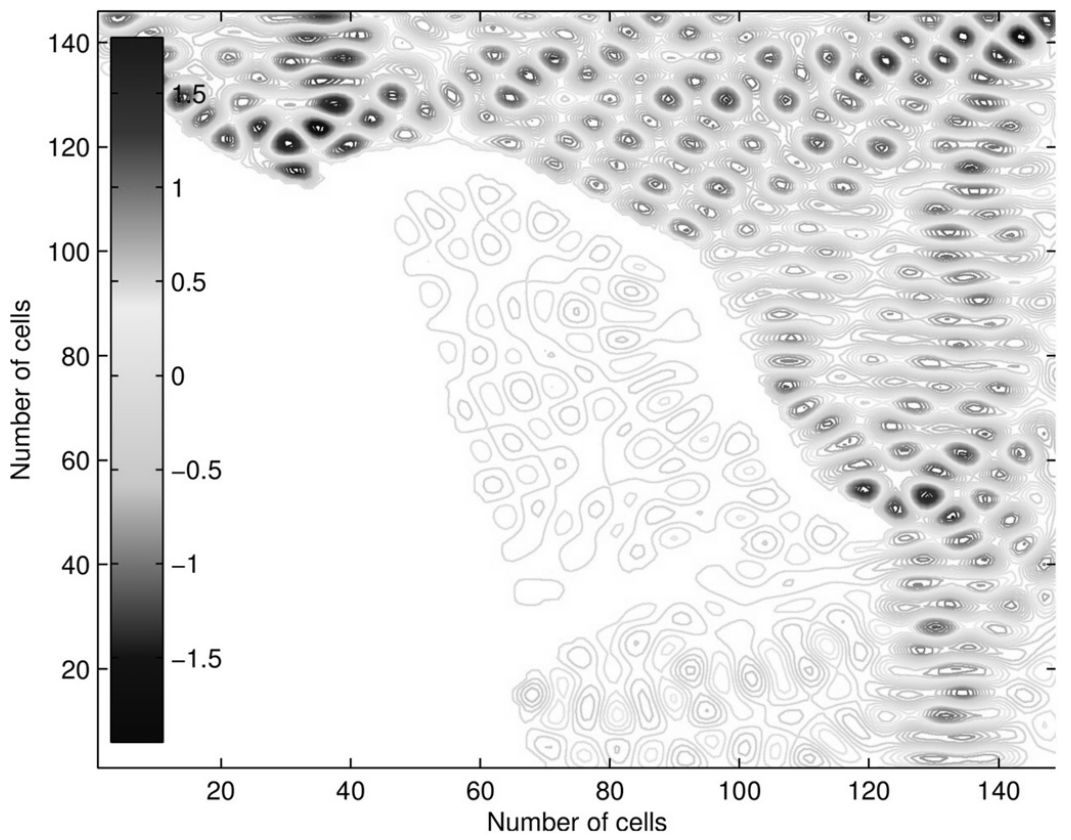

Figure 22. Stable wave heights contour distribution into the nautical marine. 


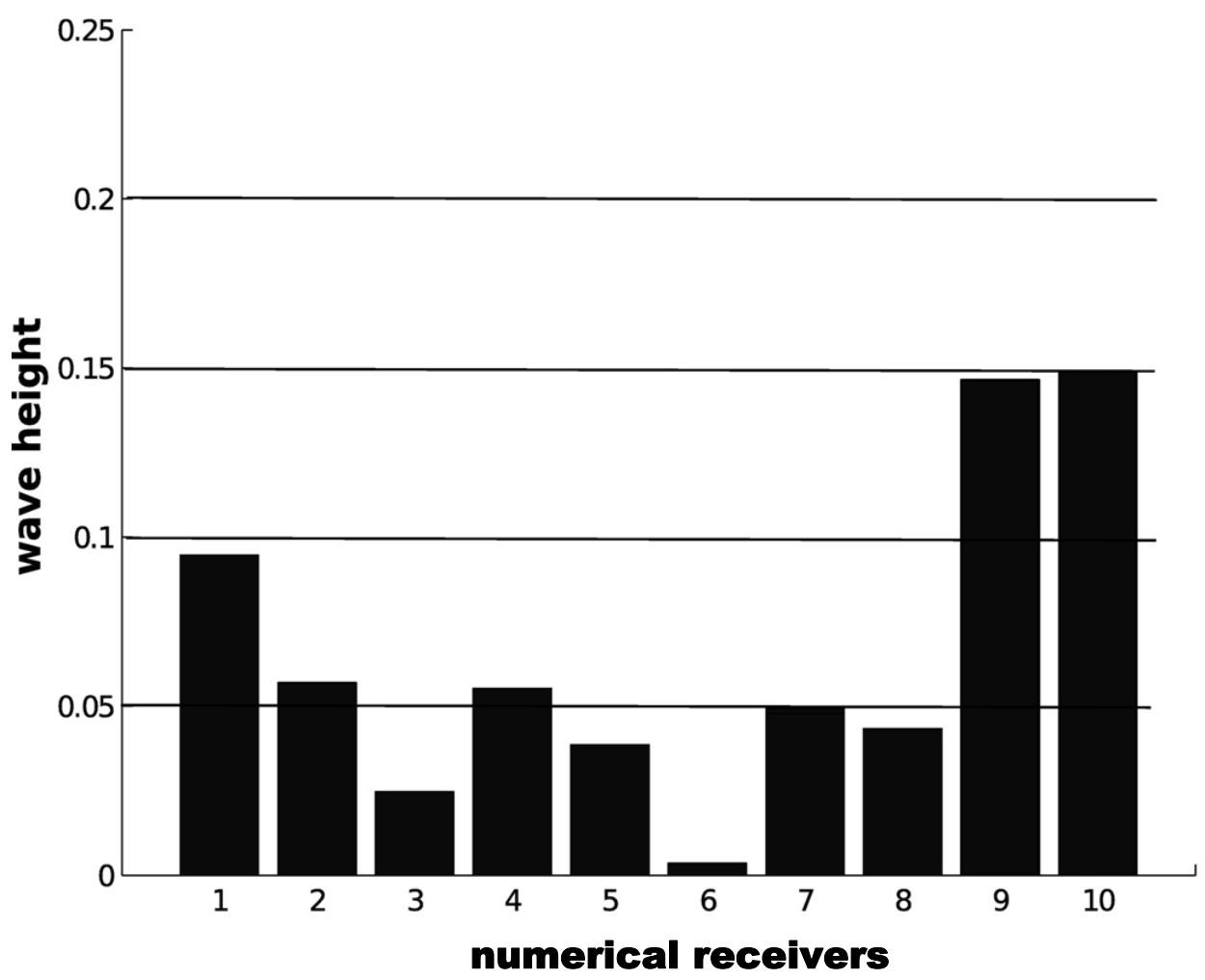

Figure 23. Stable wave height in the numerical receivers.

\section{Final remarks}

In this research we develop a very fast numerical code for the study of the wave propagation over irregular bottom topographies. The model has produced consistent results with controlled cases and the result for the coastal area of the LVNPP is very acceptable compared with the data acquired in situ. The model was also probed in a nautical marine giving the expected results.

The aim of the model is to split the governing equation, in its phase velocities components and wave height, reducing significantly the computing time and the complexity of the implementation using sparse matrices. We can solve the system over a grid of 5896 cells in just 120 s using sparse matrix algorithms in a standard workstation. The model is capable of reproducing the effects of the reflection and diffraction with accuracy and the refraction could be reproduced only for domains with cells greater or equal to $10^{2} \mathrm{~m}$. In future work we will present the sediment transport and particle transport coupled with the wave transformations.

\section{Nomenclature}

$C$ : Phase velocity $(\mathrm{m} / \mathrm{s})$

$Q_{X}$ : Phase velocity in the $\mathrm{x}$ direction $(\mathrm{m} / \mathrm{s})$

$Q_{Y}$ : Phase velocity in the y direction $(\mathrm{m} / \mathrm{s})$

$\eta$ : Wave heights $(\mathrm{m})$

$\omega:$ Angle of frequency (angle in radians)

$\varphi$ : Wave potential function

$n$ : Group factor

$K_{L}$ : Reflection factor 


\section{References}

[1] J.C.W. Berkhoff. Computation of combined refractiondiffraction. Proc. 13th Coastal Eng. Conf., pages 471490, 1972.

[2] Couder C., Ramírez H., and Herrera E. Numerical Modeling of Coupled Phenomena in Science and Engineering: Practical Use and Examples, volume 1 of Multiphysics modeling, chapter 34. Numeric optimization of the hydrodynamic model YAXUM/3D. Taylor \& Francis, 2008.

[3] Rodríguez C., Serre E., Rey C., and Ramírez H. Numerical investigation of wake formation around a conical island in shallow-water flows. In Proceedings of the WSEAS International Conference on Environment, Ecosystems and Development, pages 2-4, Venice, Nov 2005.

[4] Rodríguez C., Serre E., Rey C., and Ramírez H. A numerical model for shallow-water flows: dynamics of the eddy shedding. Wseas Transactions on Environment and Development, 1(2), 2005.

[5] J.M.G. Copeland. A practical alternative to the mildslope wave equation. Coastal Engineering, 9:125-149, 1985.

[6] Zeki Demirbilek and Vijay Panchang. Cgwave: A coastal surface water wave model of the mild slope equation. Technical Report Technical Report CHL-98-xx, Prepared for Headquarters, U.S. Army Corps of Engineers, 1998.

[7] Herrera E., Ramírez H., and Couder C. Numerical Modeling of Coupled Phenomena in Science and Engineering: Practical Use and Examples, volume 1 of Multiphysics modeling, chapter 12 . Numerical modeling of wave phenomena (refraction-diffraction) applied to breakwaters of the cooling water intake of Laguna Verde nuclear power plant in Veracruz, Mexico. Taylor \& Francis, 2008

[8] J.R. Houston. Combined refraction and diffraction using finite element methods. Appl Ocean Res, 3(4):163$170,1981$.

[9] A. Inan and L. Balas. Numerical modeling of mild slope equation with finite volume method. WSEAS Transactions on Mathematics, 7(5):234-243, 2008. Cited By (since 1996): 2.

[10] A. Inan and L. Balas. Numerical modeling of extended mild slope equation with modified maccormack method. WSEAS Transactions on Fluid Mechanics, 4(1):14-23, 2009.

[11] J.J. Lee. Wave-induced oscillations in harbors of arbitrary geometry. Fluid Mech, 45:375-394, 1971.

[12] B. Li and K. Anastasiou. Efficient elliptic solvers for the mild-slope equation using the multigrid technique. Coastal Engineering, 16:245-266, 1985.

[13] B. Li and C. A. Fleming. Solving mild-slope equation by explicit scheme. Proceedings of the Institution of Civil Engineers: Maritime Engineering, 157(4):175-182, 2004.

[14] P. Lin. A compact numerical algorithm for solving the time-dependent mild slope equation. International Journal for Numerical Methods in Fluids, 45(6):625-642, 2004. Cited By (since 1996): 6.

[15] J. Maa, M.H. Maa, C. Li, and Q. He. Using the gaussian elimination method for large banded matrix equations. Technical Report 135, Virgina Institute of Marine Science, 1997.

[16] Roland Martin; and Carlos Couder-Castaneda. An improved unsplit and convolutional perfectly matched layer absorbing technique for the navier-stokes equations using cut-off frequency shift. CMES: Computer Modeling in Engineering \& Sciences, 63(1), 2010.

[17] F. S. B. F. Oliveira and K. Anastasiou. An efficient computational model for water wave propagation in coastal regions. Applied Ocean Research, 20(5):263271, 1998. Cited By (since 1996): 19.

[18] V. Panchang and Pearce B. Solution of mildslope wave problem by iteration. Journal of Applied Ocean Research, 13:187-200, 1991.

[19] Hermilo Ramírez-León, Hector. Barrios-Piña, Clemente Rodriguez-Cuevas, and Carlos CouderCastañeda. Baroclinic mathematical modeling of fresh water plumes in the interaction river-sea. International Journal of Numerical Analysis \& Modeling, 2:1-14, 2005.

[20] Hermilo Ramírez-León, Clemente RodriguezCuevas, and Herrera-Díaz Enrique. Multilayer hydrodinamic model and their application to sediment transport in estuaries. Special Issue 12 Shangai Conference, Current Trends in High Performance Computing and Its Applications, Springer-Verlag, pages 59-70, 2005.

[21] X. Shu, S. Jiang, and R. Li. Numerical simulation of engineering wave for zhongzui bay. In Proceedings of the International Conference on Offshore Mechanics and Arctic Engineering - OMAE, volume 4, pages 661-668, 2007. 
[22] Z. Song, H. Zhang, J. Kong, R. Li, andW. Zhang. An efficient numerical model of hyperbolic mild-slope equation. In Proceedings of the International Conference on Offshore Mechanics and Arctic Engineering - OMAE, volume 5, pages 253-258, 2007.

[23] T-K. Tisay and PL-F Liu. Combined refraction and diffraction using finite element methods. Appl Ocean Res, 5(1):5925-5938, 1983.

[24] F. Tong, Y. Shen, J. Tang, and L. Cui. Numerical modeling of the hyperbolic mild-slope equation in curvilinear coordinates. China Ocean Engineering, 24(4):585-596, 2010. Cited By (since 1996): 1.

[25] U. Unluate and C.C. Mei. Long wave excitation in harbors an analytical study. Technical Report 171, Parsons Lab MIT, 1973.

[26] H. Zhang, H. Zhao, and Z. Shi. Finite difference approach to the time-dependent mild-slope equation. China Ocean Engineering, 21(1):65-76, 2007. Cited By (since 1996): 4.

[27] Y. Zhang, R. Li, J. Liu, and X. . Pan. Numerical simulation of the nonlinear parabolic mild-slope equation. Shuidonglixue Yanjiu yu Jinzhan/Chinese Journal of Hydrodynamics Ser.A, 25(1):44-49, 2010.

\section{Acknowledgments}

We would like to thank the reviewers their helpful comments to improve this article and also to engineer Ivan Campos the problem statement. 


\section{Authors' Biographies}
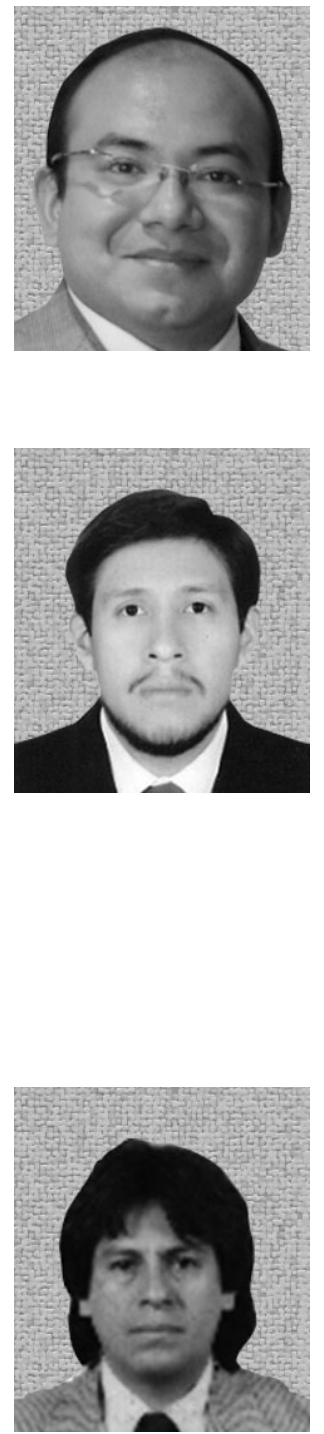

\section{Israel Enrique HERRERA-DÍAZ}

$\mathrm{He}$ is a civil engineer by Instituto Politécnico Nacional (National Polytechnical Institute), IPN-ESIA, Mexico, in 1999. He obtained his M. Sc. degree in hydraulics in 2004 from the same Institution. He is currently pursuing his PhD degree in the civil engineering program of the UNAM and works in a research project in the Centro de Investigación en Matemáticas (Mathematics Research Center), CIMAT, Guanajuato, Mexico.

\section{Carlos COUDER-CASTAÑEDA}

He received his $B$. Sc. degree in applied mathematics from the UNAM, Mexico, in 1999, the M. Sc. degree in computer science in 2004 from Centro de Investigación en Computación (Research Center for Computing), CIC-IPN, Mexico and the Ph. D. degree in industrial mathematics from the Mexican Petroleum Institute (IMP) in 2009. He did his postdoctoral studies at the Laboratoire d'Imagerie et de Modéisation en Géosciences, Université de Pau et des Pays de l'Adour (University of Pau and the Countries of Adour), France. His research interests include the numerical solution of the Navier-Stokes, shallow waters and the wave equations with perfectly matched layers for geophysical flows using high performance computing. Currently, he is member of the National System of Researchers (SNI) and works in a SERNER-CONACYT project at the IMP.

\section{Hermilo RAMÍREZ-LEÓN}

He graduated from Universidad Nacional Autónoma de México (National Autonomous University of Mexico), UNAM, as a civil engineer in 1984. Dr. Ramírez-León obtained his master's degree in hydraulics from the same university in 1988 and his Ph.D in fluid dynamics and transfer process from Ecole Centrale de Nantes (Central School of Nantes), France, in 1992. He has held different positions : in France in 1993, from 1982 to 1988 at the Engineering Institute, UNAM, from 1988 to 1991 at Ecole Centrale de Nantes, France, from 1991 to 1996 at Instituto de Investigaciones Eléctricas (Institute for Electrical Research), Mexico, from 1996 to 2002 at Instituto de Investigación del Agua (Water Research Institute), Mexico, and from 2002 to present at the Mexican Institute of Petroleum. He has authored or coauthored 16 articles, 88 communications in congresses, 13 divulgation articles, 3 Books, 6 book chapters, 38 research and technological development projects, 41 lectures and seminars. Finally, he has mentored 6 bachelor's degree students, 19 master's degree thesis students and $4 \mathrm{PhD}$ degree students. 